\title{
Design of Waterborne Nanoceria/Polymer Nanocomposite UV-Absorbing Coatings: Pickering versus Blended Particles
}

Ignacio Martín-Fabiani, ${ }^{1,}$ * Ming Liang Koh, ${ }^{2}$ Florent Dalmas, ${ }^{3}$ Katrin L. Elidottir, ${ }^{4}$ Steven J. Hinder, ${ }^{5}$ Izabela Jurewicz, ${ }^{4}$ Muriel Lansalot, ${ }^{2}$ Elodie Bourgeat-Lami ${ }^{2}$ and Joseph L. Keddie ${ }^{4}$

${ }^{1}$ Department of Materials, Loughborough University, Loughborough LE11 3TU, Leicestershire, United Kingdom

${ }^{2}$ Univ Lyon, Université Claude Bernard Lyon 1, CPE Lyon, CNRS, UMR 5265, Chemistry, Catalysis, Polymers \& Processes (C2P2), 43 Bd du 11 Novembre 1918, 69616 Villeurbanne, France.

${ }^{3}$ Univ Lyon, INSA Lyon, CNRS, Material Science and Engineering (MATEIS) UMR 5510, 7 av J. Capelle, F-69621 Villeurbanne, France

${ }^{4}$ Department of Physics, University of Surrey, Guildford GU2 7XH, United Kingdom

${ }^{5}$ Surface Analysis Laboratory, Department of Mechanical Engineering Sciences, University of Surrey, Guildford GU2 7XH, United Kingdom

\section{ABSTRACT}

Nanoparticles of cerium dioxide (or nanoceria) are of interest because of their oxygen buffering, photocatalytic ability, and high UV absorption. For applications, the nanoceria can be incorporated in a polymer binder, but questions remain about the link between the nanoparticle distribution and the resulting nanocomposite properties. Here, the thermal, mechanical and optical properties of polymer/ceria nanocomposites are correlated with their nanostructures. Specifically, nanocomposites made from waterborne Pickering particles with nanoceria shells are compared to nanocomposites made from blending the equivalent surfactant-free copolymer particles with nanoceria. Two types of nanoceria (protonated or citric acid-coated) are compared in the Pickering particles. A higher surface coverage is obtained with the protonated ceria, which results in a distinct cellular structure with nanoceria walls within the nanocomposite. In the blend of particles, a strong attraction between the protonated nanoceria and the acrylic acid groups of the copolymer likewise leads to a cellular structure. This structure offers transparency in the visible region combined with strong UV absorption, which is desired for UV blocking coating applications. Not having an attraction to the polymer, the citric acid-coated nanoceria forms agglomerates that lead to undesirable light scattering in the nanocomposite and yellowing. This latter type of nanocomposite coating is less effective in 
protecting substrates from UV damage but provides a better barrier to water. This work shows how the nanoparticle chemical functionalization can be used to manipulate the structure and to tailor the properties of UV-absorbing barrier coatings.

Key words: Ultraviolet absorption; film formation; Pickering; coatings; cerium dioxide; nanocomposites 


\section{Introduction}

In recent years, cerium dioxide $\left(\mathrm{CeO}_{2}\right)$ - especially in the form of nanoparticles, known as nanoceria has attracted the interest of both industrial and academic communities because of its high reactivity and its oxygen buffering capacity, ${ }^{1,2}$ which originate from its atomic surface structure. ${ }^{3}$ Nanoceria's outstanding physical and chemical properties make it suitable for a wide range of applications, such as gas sensors ${ }^{4,5}$ and catalyzers. ${ }^{6,7}$ Moreover, the fact that it is relatively transparent in the visible region of the spectrum but a strong absorber in the UV offers great potential in the fields of photovoltaics ${ }^{8,9}$ and sunscreen products. ${ }^{10}$ In particular, hybrid ceria/polymer particle systems are of special interest in the development of protective coatings. ${ }^{11-13}$ In the presence of other pigments, such as titanium dioxide, within a protective coating, cerium dioxide lowers the global photocatalytic activity. ${ }^{14}$ This minimizes the generation of free radicals, which otherwise degrade organic materials present in the underlying substrate, such as lignin in wood.

As an alternative to multi-step chemical modifications, ${ }^{15,16}$ a simple method to fabricate colloidal nanocomposites is to use physical mixtures of colloidal polymer particles and inorganic nanomaterials suspended in either water or an organic solvent. ${ }^{17}$ Numerous examples of nanocomposites prepared using a mixing process can be found in the literature for a wide range of inorganic particles: graphene, ${ }^{18}$ carbon nanotubes, ${ }^{19}$ clays, ${ }^{20}$ silica ${ }^{21}$ and various oxides. ${ }^{22}$ This wet colloid mixing process is simple and effective. However, one of the main challenges is preventing the inorganic nanofiller from agglomerating in large clusters when stability is poor or when the filler's attraction to the polymer particles is weak. During the film formation process, as depicted in Figure 1a, free inorganic nanoparticles can accumulate in clusters at polymer particle boundaries. The occurrence of aggregates leads to void formation, resulting in the deterioration of mechanical ${ }^{23}$ and electrical ${ }^{24}$ properties and in the development of opacity. ${ }^{25}$ 
(a)
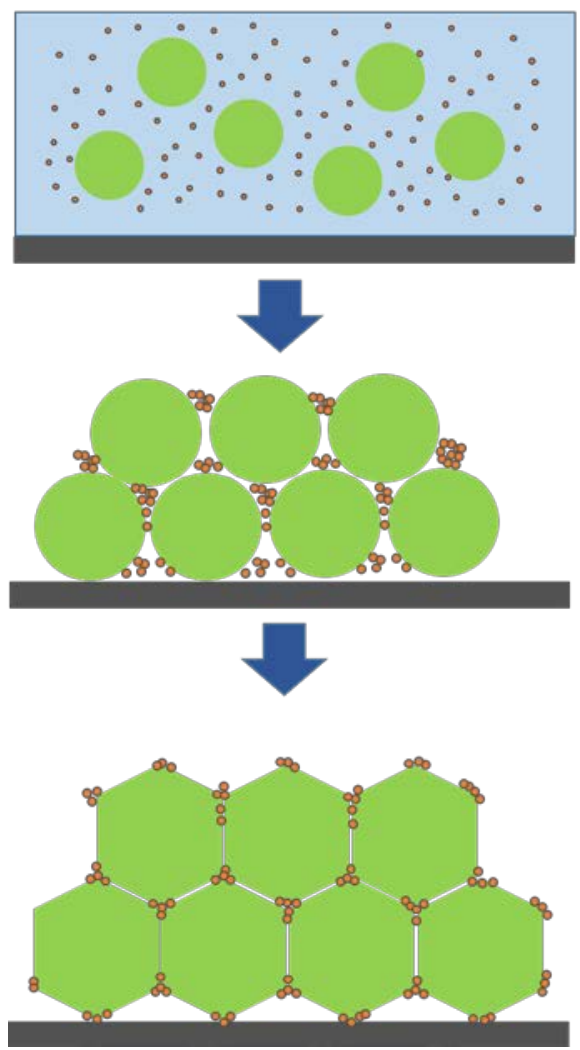

(b)
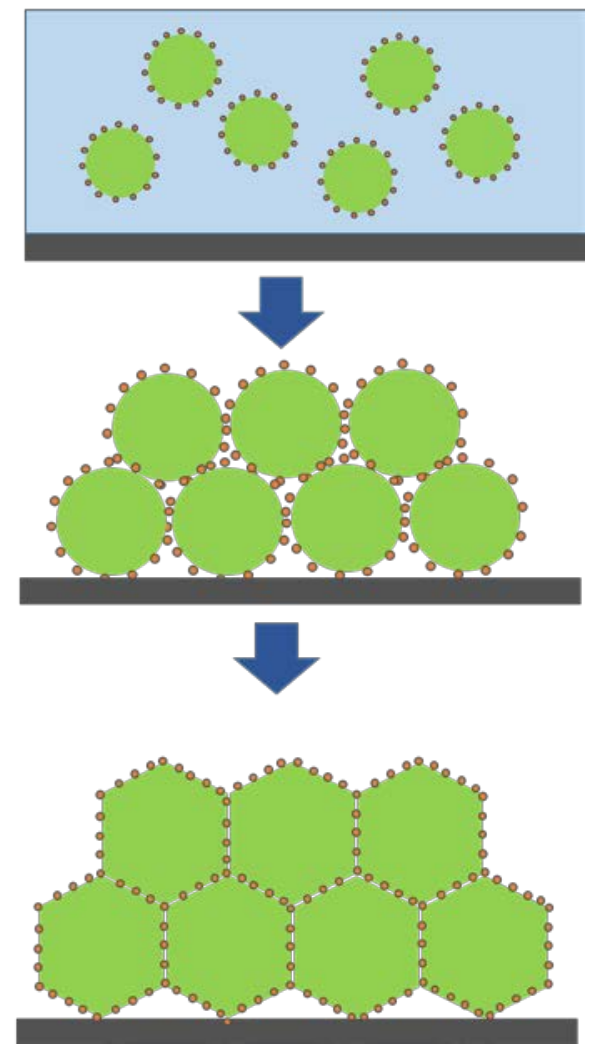

Figure 1. Sketch of the film formation process for (a) physical mixture of colloidal polymer particles (in green) and inorganic nanoparticles (in brown) with a weak interaction and (b) armored Pickering particles with an inorganic nanoparticle shell around a soft polymer core. The three main stages of this process are pictured, from top to bottom: (1) wet dispersion on a substrate, (2) particle packing, and (3) particle deformation leading to coalescence.

One possibility to solve this problem is tailoring the synthesis process to pre-build an inorganic nanostructure that will avoid the occurrence of this aggregation. In the case of waterborne polymer latexes, consisting of polymer nanoparticles suspended in water, a nanostructure with an inorganic shell can be achieved through Pickering emulsion polymerization. ${ }^{26,27}$ In this type of synthesis, inorganic materials are used as solid stabilizers in an emulsion polymerization process, preventing the growing latex particles from flocculating. ${ }^{28,29}$ The addition of a small amount of a hydrophilic comonomer favors the interaction of the inorganics with the polymer: It can interact in situ with the inorganic particles (via electrostatic interaction, surface complexation or hydrogen 
bonding) and provide suitable affinity of the growing polymer chains with their surface. ${ }^{30}$ In this way, the inorganic nanoparticles are bonded to the polymer particle surface, thus ensuring that during film formation they will not migrate and aggregate in clusters. Furthermore, any deleterious effects of surfactants are avoided.

As Figure 1b proposes, the polymer cores of Pickering particles are expected to deform and fill space to create a three-dimensional honeycomb-like nanostructure. The shells composed of inorganic nanoparticles are expected to create the cellular walls, as has been found in films from other Pickering systems. ${ }^{31,32}$

Creating Pickering particles requires optimization of the polymerisation process for each type of inorganic particles considered, especially for development at the industrial scale, and demonstration in applications when in the form of coatings. However, Pickering latex particles have been synthesized using zinc oxide nanoparticles to create binder films for printing applications. ${ }^{33}$ In another application, soft latex with Pickering clay shells were added to pressure-sensitive adhesives and found to provide synergistic mechanical properties that were not found from physical mixtures of the constituent clay and polymer particles. ${ }^{34}$

Until now, the emphasis of the studies on ceria/polymer hybrid latexes has been primarily placed on the synthesis of these systems, using either living polymer chains as both coupling agents and stabilizers ${ }^{35,36}$ or without any stabilizer using miniemulsion polymerization, ${ }^{30}$ or the possibility of using ceria with different geometries such as nanorods. ${ }^{12}$ Generally, the mechanical and thermal properties of the final dried films were not presented in these previous works. Only a few publications report on their optical properties, ${ }^{12,13,37}$ reporting an increase in UV absorbance with increasing amount of ceria content. ${ }^{13}$ Importantly, the effect of the filler distribution on the final properties has not yet been assessed. To our knowledge, a comparison of Pickering nanocomposites with physical blends containing the same amount of nanoceria but without the pre-designed architecture that the Pickering chemistry provides has not been reported in the literature yet. 
In this work, we design and fabricate polymer/nanoceria nanocomposite coatings using Pickering emulsion particles as the building blocks. We compare the structure and resulting properties to a nanocomposite prepared by the physical blending of the corresponding polymer particles and ceria nanoparticles in water. Of particular interest here is how the distribution of ceria nanoparticles can be used to increase the UV absorption without compromising the nanocomposite's optical transparency in the visible range. This combination of properties is desirable for wood coating ${ }^{38}$ and for display screens that are subject to UV/ozone degradation. A particular problem has been reported in the UV degradation of silver nanowires ${ }^{39}$ that are used in optically transparent conducting films for display applications. We also investigate how the ceria distribution influences mechanical and water barrier properties. The results presented here provide a valuable guide to determine which nanocomposite fabrication route should be chosen depending on the final properties that are needed.

\section{Experimental Details}

\subsection{Materials}

Two types of cerium oxide $\left(\mathrm{CeO}_{2}\right)$ nanoparticles were used. They were both provided by Solvay (Aubervilliers, France) as stable aqueous dispersions of $\mathrm{CeO}_{2}$ nanocrystals, $7 \mathrm{~nm}$ in diameter, as determined by dynamic light scattering. The acidic sol (13.1 wt\% solids content) is composed of cationic particles stabilized at low $\mathrm{pH}$ (typically $\mathrm{pH}<2$ ) via electrostatic repulsion between the protonated hydroxyl groups. ${ }^{30}$ It was compared to a citric acid-coated ceria dispersion with $21.6 \mathrm{wt} \%$ solids content and $\mathrm{pH}=9$, commercialized under the brand name Rhodigard ${ }^{\circledR}$ W200. Both sols were used as received. Methacrylic acid (MAA, $99 \%$; Sigma-Aldrich), n-butyl acrylate (BA, 99 \%; Acros Organics), methyl methacrylate (MMA, 99 \%; Acros Organics), 2,2'-azobis(2-methylpropionamidine) dihydrochloride (AIBA, $97 \%$; Sigma-Aldrich), and ammonium persulfate (APS, 98+\%; Acros Organics) were used without further purification. Deionized water was used for synthesis. In-house nitrogen gas $\left(\mathrm{N}_{2(\mathrm{~g})}\right)$ was used for purging.

\subsection{Synthesis and preparation of blends}


Emulsion polymerization was carried out in a $500 \mathrm{~mL}$, 4-necked, double-walled reactor, jacketed with a temperature controlled water bath, and equipped with a stirrer (overhead, glass, anchor-type), a condenser, nitrogen inlet, and a valve to remove the latex.

Surfactant-free blank latex. BA (45.3 g), MMA (30.0 g), MAA (0.20 g) and water (158.8 g) were transferred to the pre-heated reactor $\left(70^{\circ} \mathrm{C}\right)$ and purged with $\mathrm{N}_{2(\mathrm{~g})}$ for $30 \mathrm{~min}$. AIBA (0.375 g) was dissolved in water (9.9 g), purged with $\mathrm{N}_{2(\mathrm{~g})}$ for $30 \mathrm{~min}$, then injected into the reactor. Polymerization took place at $70^{\circ} \mathrm{C}$ with stirring for $5 \mathrm{~h}$, then exposing the reaction to air and cooling with an ice/water-cold bath. The latex was passed through a fabric filter $(100 \mu \mathrm{m})$ to obtain the final surfactant-free latex. We will refer to it hereafter as SFB (for "surfactant-free blank") because it is free of ceria. The latex characteristics are summarized in Table 1.

Acidic ceria sol Pickering latex. The acidic sol (41.93 g, 13.1 wt $\left.\% \mathrm{CeO}_{2}\right)$ was diluted with water (117.6 g). MAA (0.204 g, $1.9 \mu \mathrm{mol} \mathrm{m}{ }^{-2}$ of $\mathrm{CeO}_{2}$ ) was dissolved in water (5.1 g) and added dropwise to the diluted acidic sol solution and left to stir for $1 \mathrm{~h}$ at room temperature. The ceria suspension, BA (45.5 g), and MMA (30.0 g), were transferred to the pre-heated reactor $\left(70^{\circ} \mathrm{C}\right)$ and purged with $\mathrm{N}_{2(\mathrm{~g})}$ for $30 \mathrm{~min}$. AIBA $(0.375 \mathrm{~g})$ was dissolved in water $(10.0 \mathrm{~g})$, purged with $\mathrm{N}_{2(\mathrm{~g})}$ for $30 \mathrm{~min}$, then injected into the reactor. Polymerization took place at $70^{\circ} \mathrm{C}$ with stirring for $5 \mathrm{~h}$, then exposing the reaction to air and cooling with an ice/water-cold bath. The latex was passed through a fabric filter (100 $\mu \mathrm{m}$ ) to obtain the acidic sol Pickering latex, which is referred to as ACS for brevity (see Table 1).

Basic ceria sol (Rhodigard ${ }^{\circledR}$ ) Pickering latex. The Rhodigard ${ }^{\circledR}$ suspension (41.68 g, $21.6 \mathrm{wt} \% \mathrm{CeO}_{2}$ ) was diluted with water (215.5 g). MAA (2.032 g, $12 \mu \mathrm{mol} \mathrm{m}{ }^{-2}$ of $\mathrm{CeO}_{2}$ ) was dissolved in water (9.9 g) and added dropwise to the diluted Rhodigard ${ }^{\circledR}$ sol and left to stir for $1 \mathrm{~h}$ at room temperature. The ceria suspension, BA (72.9 g), and MMA (48.1 g), were transferred to the pre-heated reactor $\left(70{ }^{\circ} \mathrm{C}\right)$ and purged with $\mathrm{N}_{2(\mathrm{~g})}$ for $30 \mathrm{~min}$. APS $(0.601 \mathrm{~g})$ was dissolved in water $(10.4 \mathrm{~g})$, purged with $\mathrm{N}_{2(\mathrm{~g})}$ for $30 \mathrm{~min}$, then injected into the reactor. Polymerization took place at $70^{\circ} \mathrm{C}$ with stirring for $6 \mathrm{~h} 40$ then exposing the reaction to air and cooling with an ice/water-cold bath. The latex was then passed through a fabric filter $(100 \mu \mathrm{m})$ to obtain the Rhodigard ${ }^{\circledR}$ Pickering latex (hereafter referred to as BCS 
for "basic ceria sol”). (See Table 1.) Note that the solids contents of the ACS and BCS Pickering latexes were both above $30 \mathrm{wt} \%$, which make the dispersions suitable for coatings applications. There are only a few examples in the literature in which Pickering latex was made with solids contents above 20 wt. $\% .^{27,29,40}$

Nanoceria/latex blends. The acidic nanoceria sol in water and the SFB were mixed while stirring to prepare physical blends to compare with the Pickering latexes. As a result, a physical blend (called PB) of SFB and the acidic ceria sol was made, and the final nanocomposite contained 4.00 wt.\% ceria (based on the total mass).

Table 1. Experimental conditions and characteristics of the control latex, latexes obtained by Pickering emulsion polymerization in the presence of ceria and physical blend of latex and ceria nanoparticles

\begin{tabular}{|c|c|c|c|c|c|c|c|}
\hline Sample & $\begin{array}{c}\mathrm{CeO}_{2} \\
(\mathrm{wt} \%)^{\mathrm{c}}\end{array}$ & $\begin{array}{c}\text { Conversion } \\
(\%)^{d}\end{array}$ & $\begin{array}{c}\text { Latex } \\
\text { Solids } \\
\text { (wt.\%) }^{\mathrm{e}}\end{array}$ & $\begin{array}{c}\text { Particle } \\
\text { Diameter } \\
D_{\mathrm{h}}(\mathrm{nm}) \mathrm{f}\end{array}$ & $\underset{\mathrm{g}}{\text { PDI }}$ & $\begin{array}{l}\text { Polymer } \\
T_{g}\left({ }^{\circ} C\right)^{h}\end{array}$ & pH \\
\hline $\mathrm{SFB}^{\mathrm{a}}$ & 0 & 99.3 & 29.9 & 810 & 0.08 & $-21,+25$ & 2.9 \\
\hline $\operatorname{ACS}^{a}$ & 5.11 & 99.9 & 32.1 & 590 & 0.20 & -4.3 & 1.7 \\
\hline $\mathrm{BCS}^{\mathrm{a}}$ & 5.75 & 100 & 32.7 & 1000 & 0.50 & +1.9 & 6.5 \\
\hline $\mathrm{PB}^{\mathrm{b}}$ & 4.00 & - & 28.9 & - & - & - & - \\
\hline
\end{tabular}

a Obtained by surfactant-free emulsion polymerization. ${ }^{\mathrm{b}}$ Obtained by blending SFB with the acidic ceria sol. ${ }^{\mathrm{c}}$ As determined by thermogravimetric analysis (TGA). ${ }^{\mathrm{d}}$ Final monomer conversion during polymerization, expressed in weight $\%$ as determined by gravimetry. ${ }^{e}$ As determined by gravimetry. fParticle diameter and ${ }^{g}$ polydispersity index as determined by DLS. Correlograms and particle size distributions can be found in the Supporting Information (Figures S1 and S2). A comparative size analysis obtained from atomic force microscopy and cryo-TEM of dry and wet particles, respectively, is presented in Figure S3. ${ }^{\mathrm{h}}$ Glass transition temperature as determined by DSC.

\subsection{Characterization Methods}

Dynamic light scattering (DLS). The hydrodynamic particle diameters $\left(D_{\mathrm{h}}\right)$ and polydispersity index (PDI) were determined via DLS (Zetasizer Nano ZS, from Malvern Instruments) using a $633 \mathrm{~nm}$ laser 
and a detector angle of $173^{\circ}$. Correlograms were fit by the cumulant method, averaging three measurements for each sample.

Differential scanning calorimetry (DSC) was performed using a Q1000 calorimeter (TA Instruments, New Castle, DE, USA) under nitrogen flow $\left(50 \mathrm{~mL} \mathrm{~min}^{-1}\right)$. For sample preparation, a drop of the latex under study was cast onto poly(tetrafluorethylene) blocks and dried at room temperature under ambient conditions. The dried samples had a mass of 8-10 mg. For the glass transition analysis, the temperature was ramped from -80 to $130{ }^{\circ} \mathrm{C}$ at $10{ }^{\circ} \mathrm{C} \mathrm{min}{ }^{-1}$. For water sorption experiments, pieces of dried films were immersed in deionized water for three days. The sample was then introduced in an aluminium pan and submitted to a cooling $\left(25\right.$ to $-80^{\circ} \mathrm{C}$ at $\left.10^{\circ} \mathrm{C} \min ^{-1}\right)$ and heating $\left(-80\right.$ to $90^{\circ} \mathrm{C}$ at $10^{\circ} \mathrm{C} \mathrm{min}^{-1}$ ) cycle.

Thermogravimetric analysis (TGA). Samples of about 7-8 $\mathrm{mg}$ were prepared by casting on a poly(tetrafluoroethylene) substrate at room temperature. TGA was performed in a nitrogen atmosphere (60 $\mathrm{mL} \mathrm{min}^{-1}$ ) using a TGA Q500 instrument from TA Instruments (New Castle, USA). The temperature was ramped from room temperature to $600{ }^{\circ} \mathrm{C}$ at $10^{\circ} \mathrm{C} \mathrm{min}^{-1}$.

Microstructural observation, sectioning and imaging was performed using a dual column focused ion beam (FIB)-scanning electron microscope (SEM) ZEISS NVision40. An accelerated ion beam of $\mathrm{Ga}^{2+}$ ions was used. The sample was metalized with gold, and then a thin layer of carbon was deposited in the area to be observed. This was followed by a two-step milling procedure. First, a bulk trapezoid was milled at high current beam ( $4 \mathrm{nA}$ ) so that the shorter face could be imaged by the electron beam up to at least a $15 \mu \mathrm{m}$ depth. Then, a final polishing of the observed surface was carried out with a fine current beam ( $80 \mathrm{pA})$. The SEM images of the polished surface were then recorded under low voltage conditions (1 kV) using an in-lens secondary electron (SE) detector. Such imaging conditions allowed observing insulating materials with minimized charging effects, which provided high resolution and a good contrast between inorganic and organic phases.

Transmission electron microscopy (TEM) of cross-sections. Film mould casts were prepared by diluting the latex to $10 \mathrm{wt} \%$ and left to dry in poly(tetrafluoroethylene) moulds in ambient conditions 
over 7 days. Thin foil TEM specimens $(<100 \mathrm{~nm})$ of the mould-casted films were then prepared using a diamond knife on a cryo-ultramicrotome equipment and transferred to copper TEM grids (untreated). TEM images were recorded using a Philips CM120 transmission electron microscope at an accelerating voltage of $80 \mathrm{kV}$.

Cryo-transmission electron microscopy. For cryogenic transmission electron microscopy (cryo-TEM) analyses, samples of particles in water were dropped on lacy carbon films (hydrophilized prior by argon plasma) and vitrified in liquid ethane. Cryo-TEM images were recorded using a Philips CM120 transmission electron microscope at an accelerating voltage of $120 \mathrm{kV}$.

Dynamic mechanical analysis (DMA). Dispersions were cast in poly(tetrafluoroethylene) moulds and allowed to dry under ambient conditions for 7 days. Then they were cut into strips with typical dimensions of $10 \mathrm{~mm} \times 4 \mathrm{~mm} \times 0.5 \mathrm{~mm}$. Sinusoidal stress measurements were carried out in air using a DMA Q800 from TA Instruments (New Castle, DE, USA). Experiments were performed in the tensile mode at a frequency of $1 \mathrm{~Hz}$ with $0.05 \%$ strain. The temperature was ramped from $-50{ }^{\circ} \mathrm{C}$ to $100{ }^{\circ} \mathrm{C}$ at $3{ }^{\circ} \mathrm{C} \min ^{-1}$.

Thermomechanical analysis (TMA). Measurements of the softening point and the response under compression are of particular relevance to applications in coatings. Dispersions were cast in moulds, dried for seven days, and then cut into squares with typical dimensions of $4 \mathrm{~mm} \times 4 \mathrm{~mm} \times 0.5 \mathrm{~mm}$. The samples were analyzed with a cylindrical, flat-ended probe with a radius of $0.89 \mathrm{~mm}$ applying a constant load of $0.05 \mathrm{~N}$ using a commercial thermomechanical analyzer (TMA Q400, TA Instruments, New Castle, DE, USA) under a constant air flow $\left(50 \mathrm{~mL} \mathrm{~min}{ }^{-1}\right)$. The temperature was ramped from $-30{ }^{\circ} \mathrm{C}$ to $200{ }^{\circ} \mathrm{C}$ at $5^{\circ} \mathrm{C} \mathrm{min}^{-1}$. The softening point, $S_{200}$, was defined as the temperature at which the dimensional change under the load was $200 \mu \mathrm{m}$.

$U V$-visible spectrometry. Samples were casted on quartz cover slips $(25.4 \mathrm{~mm} \times 25.4 \mathrm{~mm})$ previously cleaned with acetone and treated inside a UV/ozone chamber (Bioforce Nanosciences, model UV.TC.EU.003). A Camspec M350 double beam spectrophotometer was used to acquire spectra from coatings in a wavelength range from 195 to $1100 \mathrm{~nm}$. The linear absorption coefficient, $\mu$, was 
calculated from the fractional intensity of light transmission as $T=\frac{I}{I_{0}}=\exp (-\mu x)$. The film thickness, $x$, was measured using a surface profiler (Dektak 150, Veeco Instruments). Spectra from the ceria sols (dilute 400 times in deionized water) were obtained using quartz cuvettes in a Shimadzu UV-Vis spectrophotometer (UV-2501PC) with a wavelength range from 195 to $900 \mathrm{~nm}$.

X-ray Photoelectron Spectroscopy (XPS). XPS analyses were performed using a ThermoFisher Scientific Instruments (East Grinstead, UK) K-Alpha+ spectrometer. XPS spectra were acquired using a monochromated $\mathrm{Al} \mathrm{K} \alpha \mathrm{X}$-ray source $(\mathrm{hv}=1486.6 \mathrm{eV})$. An X-ray spot size of $\sim 400 \mu \mathrm{m}$ radius was employed. Survey spectra were acquired employing a pass energy of $200 \mathrm{eV}$. High resolution, corelevel spectra for all elements were acquired with a pass energy of $50 \mathrm{eV}$. All spectra were charge referenced against the $\mathrm{C} 1 \mathrm{~s}$ peak at $285 \mathrm{eV}$ to correct for charging effects during acquisition. Quantitative surface chemical analyses were calculated from the high resolution, core-level spectra following the removal of a non-linear (Shirley) background. The manufacturer's Avantage software was used, which incorporates the appropriate sensitivity factors and corrects for the electron energy analyzer transmission function. The two types of sols and both the ACS and BCS nanocomposites were drop-cast onto Au-coated glass substrates and dried for two days under ambient conditions prior to XPS analysis. The Au layer was sufficiently thick to prevent photoelectron emission from the substrate.

\section{Results and discussion}

\subsection{Particle and composite structural characterization}

Several hydrophilic auxiliary comonomers have been reported in the literature to favor adsorption of Pickering stabilizers onto latex particles. ${ }^{41-43}$ Relying on the well-known affinity of carboxylic acids for rare earth metal oxides, methacrylic acid (MAA) was selected as an auxiliary comonomer in the present work. MAA adsorbs on the $\mathrm{CeO}_{2}$ surface via complexation chemistry involving interactions between the carboxyl groups and the Ce atoms as depicted in Figure 2a. A previous study showed that for the MAA concentration used in the present work $\left(1.9 \mu \mathrm{mol} \mathrm{m}^{-2}\right.$ of $\left.\mathrm{CeO}_{2}\right)$, the sol remained stable $\left(\mathrm{D}=9 \mathrm{~nm}, \mathrm{PDI}=0.20\right.$, versus $\mathrm{D}=7 \mathrm{~nm}, \mathrm{PDI}=0.09$ for the pristine $\left.\mathrm{CeO}_{2}\right){ }^{44}$ Therefore, after MAA 
addition and before the beginning of the polymerization, the acidic sol is effectively stable, allowing the efficient formation of inorganic-armored latex particles through either miniemulsion or emulsion polymerization..$^{30,44}$ Once the polymerization started, DLS did not indicate any stability issues during the course of the reaction.

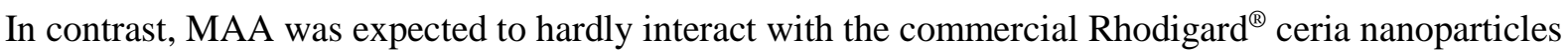
that are already coated with citric acid molecules, which may hamper nanoceria adhesion on the growing latex particles during polymerization (Figure 2b).

Cryo-TEM images obtained from the individual nanocomposite particles of the acidic sol (ACS) Pickering latex (Figure 3) show a distinct armoured morphology. The ceria nanoparticles appear as the black phase (small dots) in the particle shells. By contrast, the presence of the nanoceria in the BCS Pickering latex particles is less clear, and free ceria nanoparticles appear in the continuous phase (frozen water) as black dots. This difference in nanoceria distribution can be explained by the different surface chemistries between the two sources of ceria explained above. Indeed, a strong interaction energy is expected between the auxiliary comonomer MAA and the acidic ceria sol. In contrast, in the case of the Rhodigard ${ }^{\circledR}$ ceria nanoparticles, MAA molecules are unlikely to be able to displace adsorbed citric acid molecules.

As a result of this differing interaction strength, the acidic ceria sol stabilizes the polymer particles more efficiently than the Rhodigard ${ }^{\circledR}$ particles, resulting in smaller ACS Pickering latex particles $(590 \mathrm{~nm})$ and larger BCS particles $(1000 \mathrm{~nm})$. Furthermore, unbound Rhodigard ${ }^{\circledR}$ ceria nanoparticles can be observed in the BCS suspension, which indicates a weaker interaction.

Although the upscaling of the recipes presented here was not the main purpose of this work, it is important to consider the feasibility of the industrialization of the process. In related work reported previously, $15 \mathrm{~L}$ batches of surfactant-free latex has been synthesised via a semi-batch process under adjusted conditions. ${ }^{45}$ In the case of the ceria Pickering particles, we propose it should be possible to build on this previous success to synthesize a seed in abatch process and continue the polymerization in a semi-batch process. 
(a)

Acidic ceria sol

(c)

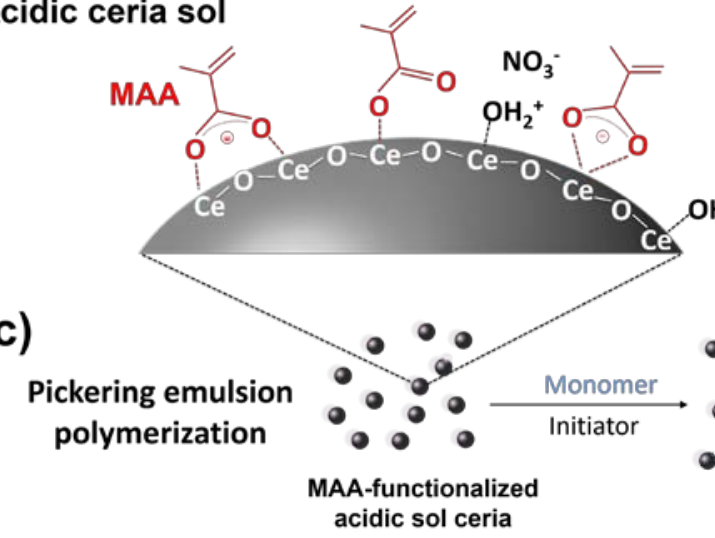

(b)

Basic ceria sol<smiles>C=C(C)C(=O)[O-]</smiles>

$\mathrm{O}=\mathrm{Na}^{+}$
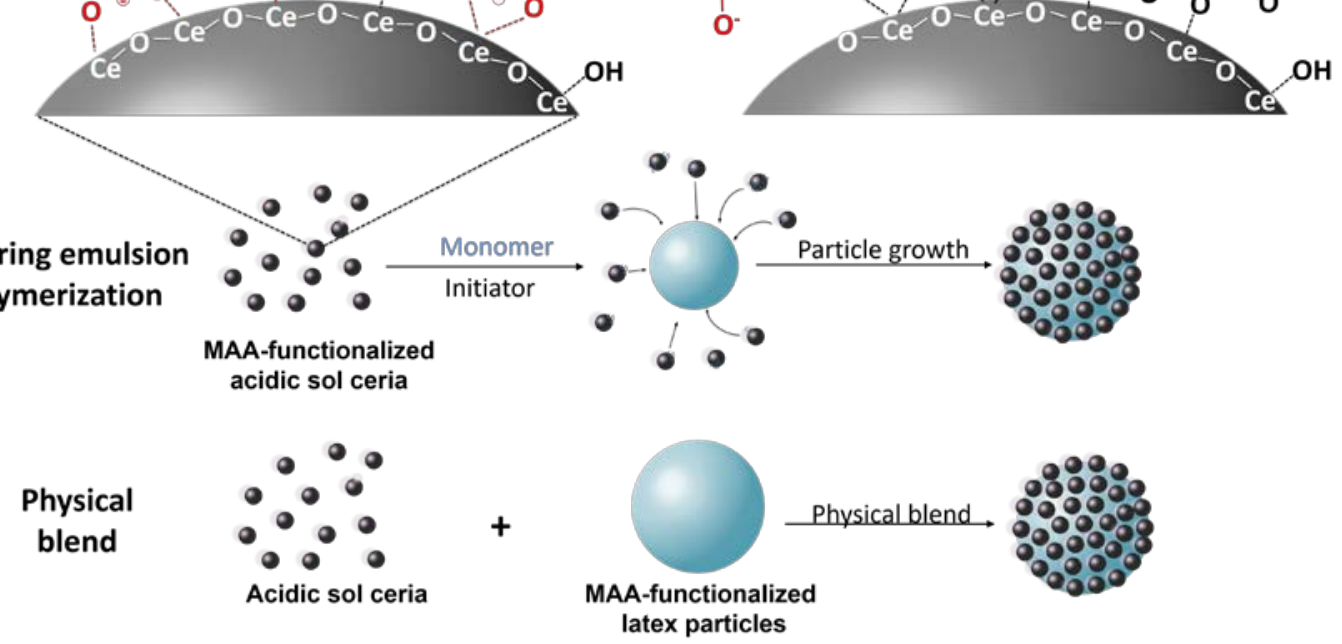

latex particles

Figure 2. Schemes depicting the surface chemistry of the (a) acidic and (b) basic ceria sol nanoparticles and interactions with MAA groups, and (c) the comparison between the Pickering emulsion polymerization and physical blend processes using the acidic ceria sol. 


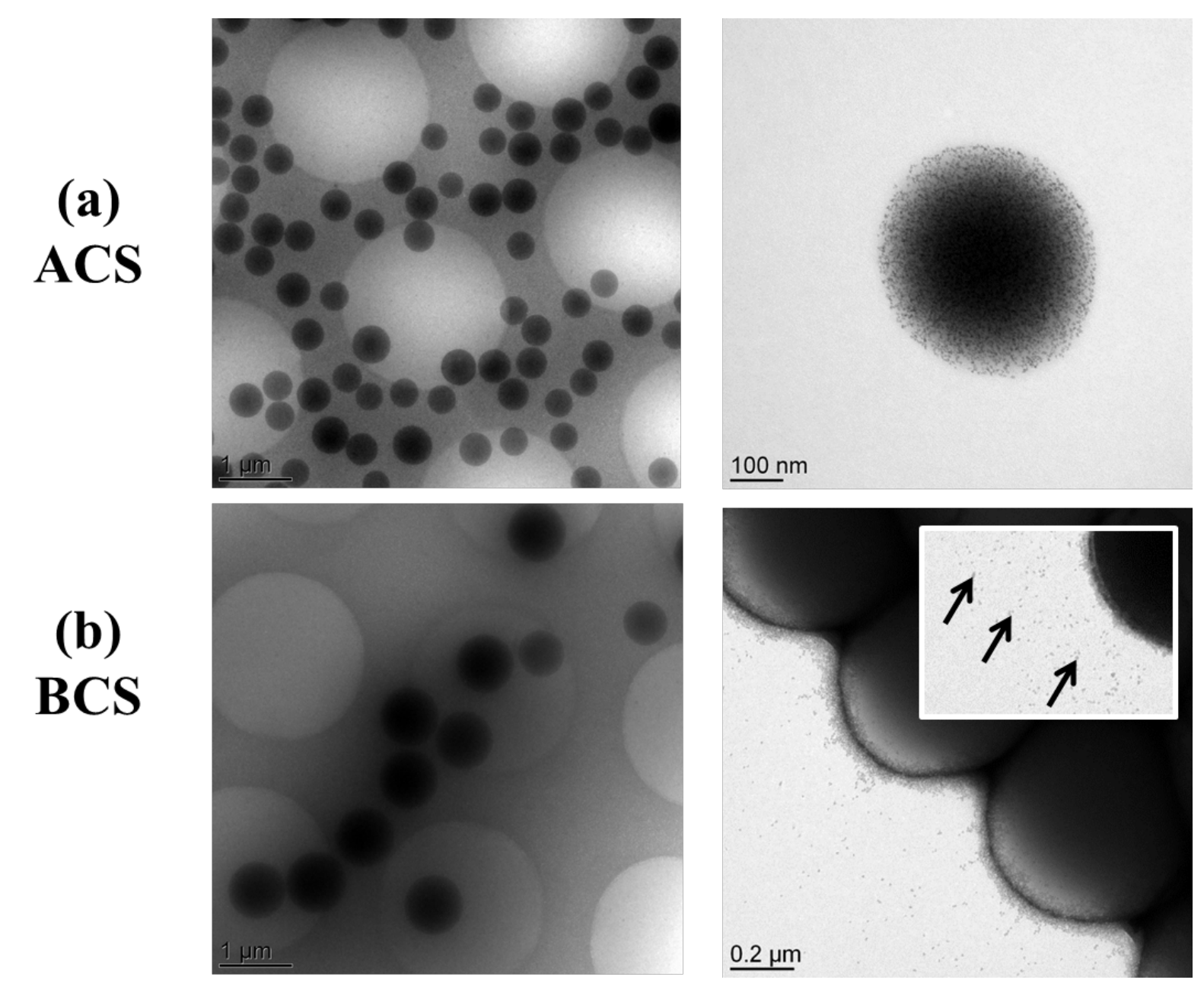

Figure 3. Cryo-TEM images of Pickering latexes synthesized using (a) acidic ceria sol (ACS), and (b) basic ceria sol (BCS). The holes in the lacy carbon substrates appear as the large, light grey circles. The continuous phase is frozen water. Free ceria particles (appearing as black dots) are indicated by arrows.

Nanocomposite latex films were prepared from the two types of nanoceria Pickering (ACS and BCS) latex dispersions and from the physical blend (PB), as already described. Despite the low Tg values (Table 1), the dried films were not sticky to the touch, although the copolymer is viscoelastic at room temperature. The copolymer composition was selected as a model system. If a harder coating is needed, the composition could be tuned to decrease the amount of BA (or to add other high- $\mathrm{T}_{\mathrm{g}}$ monomers) and thus raise the glass transition temperature. The use of FIB-SEM and TEM allowed the characterization of the internal structure, as is shown in Figure 4. By examining the left column images in Figure 4a-c, the distribution of ceria within the coating (white colour) can be elucidated and 
compared for each material. For the ACS Pickering film (Figure 4a), the ceria forms a honeycomb structure derived from the armoured structure of the latex particles, as is illustrated in Figure 1b. However, in the BCS Pickering film (Figure 4b) the ceria appears to be accumulated in clusters between the particles (indicated by arrows in the left and center columns) where they provide a physical barrier to particle deformation and the particles are prevented from coalescing. The free ceria observed in Figure $3 \mathrm{~b}$ can move around the water phase during drying and accumulate in the interstitial spaces. The boundaries between some of the particles appear to be free of ceria and are fully coalesced, as indicated by arrows in the right column. The structure is similar to the drawing in Figure 1a. Although Figure 4b suggests that the particle distribution might be bimodal, thorough cryoTEM analysis has proved that the BCS particles have a narrow polydispersity (Figure S3). The different sizes observed in the cryo-section are likely due to the cross-sectioning of the particles and not fully representative of the particle distribution. Remarkably, the physical blend film (Figure 4c) presents a honeycomb structure similar to what is seen in the ACS Pickering latex. To explain this observation, a comparison between the Pickering emulsion polymerization to obtain the ACS latex and physical blend preparation is presented in Figure 2c. The MAA-functionalized acidic ceria sol acts as a stabilizer for the Pickering emulsion polymerization process, and by the end of the reaction it remains on the particle surface. In the physical blend, the MAA groups on the latex particle surface can interact with the acidic ceria sol surface. Both processes result in armoured particle morphologies that persist during film formation, resulting in the reported honeycomb structures for the nanocomposites. TEM thin film cross-sections of the same samples (centre and right columns in Figure 4) corroborate the reported SEM morphologies. In some places, there are discontinuities in the nanoceria in the cellular walls in the $\mathrm{PB}$, whereas the nanoceria walls appear to be more continuous in the ACS cellular structure. Discontinuities in the cellular structure might be related to the lower ceria content of PB when compared to ACS (Table 1) and also to the difference in MAA available at the surface in both cases. 


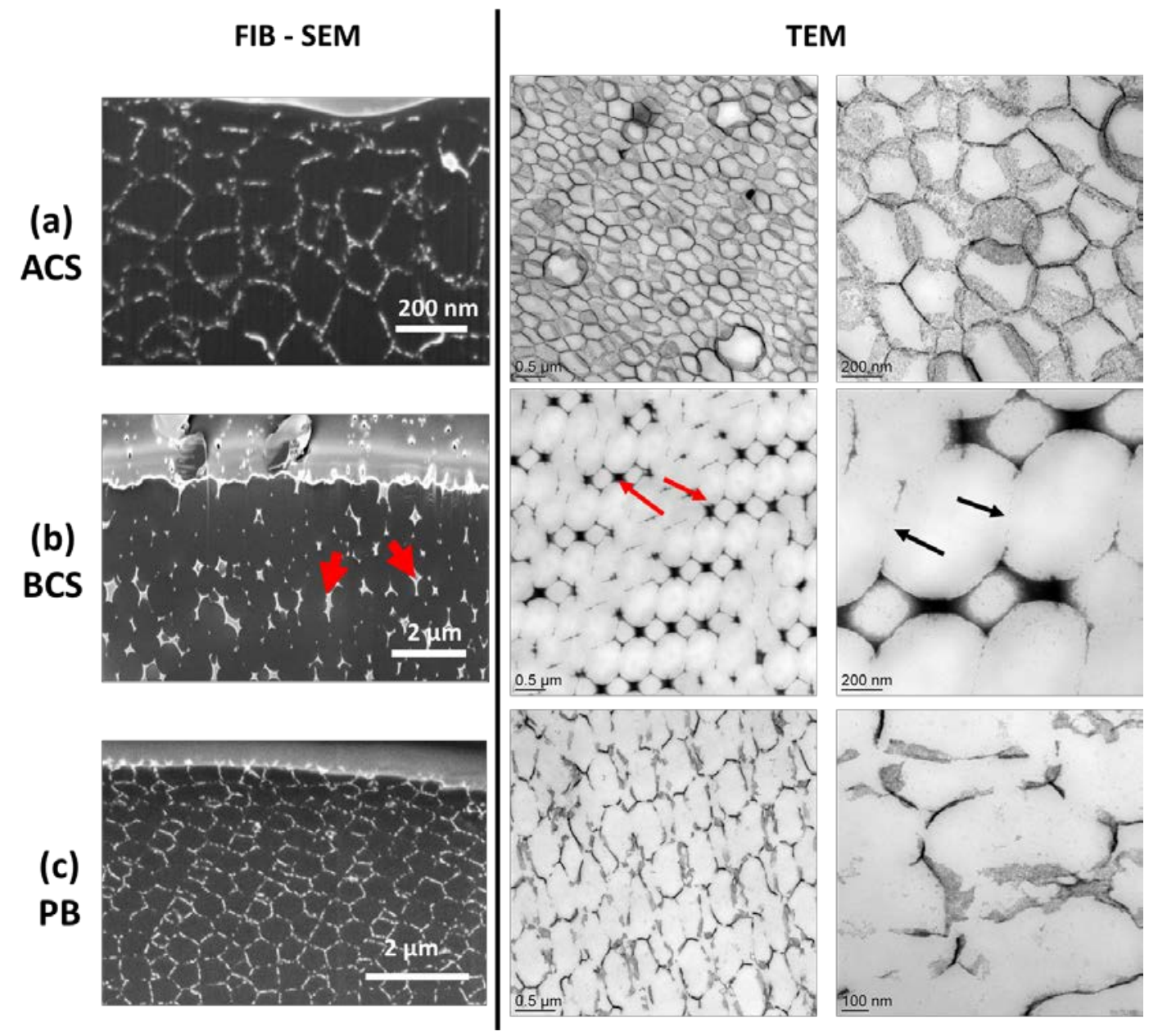

Figure 4. Microstructural characterization of the dried films of nanocomposites containing ceria: (a) Pickering latex synthesized using the acidic ceria sol (ACS), (b) Pickering latex synthesized using the basic ceria sol (BCS), and (c) physical blend of the blank polymer and acidic ceria sol (PB). Left column: FIB-SEM images of film cross-sections. Center and right columns: TEM images of thin cross-section slices. The red arrows in row (b) point out to ceria clusters (left and centre columns); the black arrows point to coalesced polymer boundaries, apparently free of ceria (right column).

In summary, the ACS nanocomposite displays a honeycomb morphology in which the nanoceria in the cell walls are bound to the polymer. The physical blend of nanoceria and blank latex possesses a similar nanostructure, but the nanoceria could be more weakly bound than in the ACS nanocomposite. In the BCS nanocomposites, the nanoceria is heterogeneously distributed with some clusters between the larger polymer particles being apparent. The honeycomb structures with inorganic nanoparticles in the cell walls in Figures 4a and c are strikingly similar to what was reported 
by Gonzalez et al. ${ }^{31}$ for Pickering particles with titanium dioxide nanoparticles in the shells. These authors attributed the particle deformation to the action of capillary pressure. In our experiments, we have not correlated the water content with the particle deformation, and we cannot comment on the relevant mechanism of the latter.

In experiments elsewhere on nanocomposites made from blends of silica nanoparticles and polymer colloids, Kobayashi et al. found that when the nanoparticles were $c a$. $50 \mathrm{~nm}$ or smaller, they blocked interdiffusion of the polymer chains across particle boundaries. However, when the nanoparticles were larger, and they approached the size of the polymer particles, they did not present an obstacle to block interfacial diffusion in the same way. ${ }^{46}$ Indeed, there is evidence elsewhere that silica nanoparticles impede interdiffusion but do not fully block it in during the film formation of silica Pickering particles. ${ }^{32}$ In the ACS and PB nanocomposites, the nanoceria at the particle boundaries could potentially block interdiffusion and lead to a weaker interface. In comparison, there appears to be greater contact between the polymer particles in the BCS nanocomposites, which could result in greater cohesive strength. We next consider how these three morphologies influence the properties of the nanocomposites.

\subsection{Thermal and mechanical properties}

Previous research $\mathrm{h}^{47,48}$ has shown that strong attractions between an inorganic filler and a polymer phase increases the thermal decomposition temperature. Hence, we consider the relative decomposition temperatures as an indirect probe of the nanoceria/polymer interaction energy. Figure S4 in the Supporting Information shows the thermal decomposition rates (as measured by the mass loss per unit temperature increase) for the three nanocomposites and the blank polymer. The temperatures of the maximum decomposition rate for the ACS Pickering and the PB nanocomposites are both relatively high $\left(390{ }^{\circ} \mathrm{C}\right.$ and $385^{\circ} \mathrm{C}$, respectively), whereas it is low for the SFB polymer (325 $\left.{ }^{\circ} \mathrm{C}\right)$. This result is consistent with the previous discussion of the ceria/MAA interactions. On the other hand, two peak temperatures in thermal decompositions are found for the BCS nanocomposite. There is one decomposition at a lower temperature $\left(324^{\circ} \mathrm{C}\right)$, which indicates the presence of non-interacting 
polymer, and a second decomposition at a higher temperature $\left(374{ }^{\circ} \mathrm{C}\right)$, which is somewhat lower than the peak temperature for the other two nanocomposites.

Dynamic mechanical properties, under a low strain, are considered next. The storage modulus, $E$ ', and the loss factor, $\tan \delta$, measured for the different ceria nanocomposites as a function of temperature are shown in Figure 5. The SFB and PB dispersions show a main broad peak and a secondary peak at around $5{ }^{\circ} \mathrm{C}$, whereas the ACS and BCS dispersions present only one broad peak. The results indicate that the presence of ceria in the film raises its storage modulus in the rubbery state and reduces its main relaxation temperature, $T_{\alpha}$ (Table 2). From the reactivity ratios of MMA and BA $\left(\mathrm{r}_{\mathrm{MMA}}=2.55\right.$ and $\left.\mathrm{r}_{\mathrm{BA}}=0.36\right)$, and their different water solubility $\left(150 \mathrm{mmol} \mathrm{L}^{-1}\right.$ and $11 \mathrm{mmol} \mathrm{L}^{-1}$ for MMA and BA, respectively), one may expect a composition drift for the copolymers. As MMA is more polar than BA, it may have a stronger affinity for the inorganic surface and be preferentially located in the vicinity of the ceria particles. ${ }^{49}$ This will decrease the MMA concentration in water and compensate for the different reactivity, which should lead to a decrease of $T_{\mathrm{g}}$ (as the copolymers would be enriched in BA units), a more homogeneous composition of the polymer chains and therefore the disappearance of the secondary peak found in SFB and PB. The shift of $T_{\mathrm{g}}$ towards a lower temperature for the physical blend compared to the blank film can be tentatively attributed to some plasticization effect by water trapped in ceria clusters, that will be studied in detail later on. Immobilization of polymer chains at the inorganic surface (via the auxiliary comonomer) as in the acidic sol Pickering film should also result in a higher $T_{\mathrm{g}}$ and this can explain why the $T_{\alpha}$ is higher for the ACS nanocomposite than for the BCS and PB. It has been reported that when a composite's storage modulus increases with the addition of a second phase, its tan $\delta$ decreases. ${ }^{50,51}$ This can be seen in the case of the ceria-stabilized latexes in Figure 5b. The decrease in the damping peak is associated with a low frictional sliding between polymer and inorganic phases and bonding between them. ${ }^{23}$

The physical blend exhibits a higher modulus at the rubbery plateau than the acidic sol Pickering latex although they both have similar microstructures. In the blend, the percolating ceria network is likely to be more cohesive (due to ceria-ceria contacts) than in the ACS nanocomposite. In the latter, the $\mathrm{CeO}_{2}$ particles are functionalized in situ by the copolymer chains formed at their surface 
and may display therefore less interaction with neighbouring $\mathrm{CeO}_{2}$ particles, which may lead to a weaker mechanical reinforcement. Interestingly, ACS and BCS films show almost identical mechanical reinforcement although their microstructures differ significantly. This effect can be explained by considering the large amount of auxiliary comonomer (MAA) that is needed for the polymerization of BCS $\left(12 \mu \mathrm{mol} \mathrm{m} \mathrm{m}^{-2}\right)$ when compared with ACS $\left(1.9 \mu \mathrm{mol} \mathrm{m} \mathrm{m}^{-2}\right)$, as the presence of MAA has been proven to enhance the mechanical properties of latex films. ${ }^{52}$ 


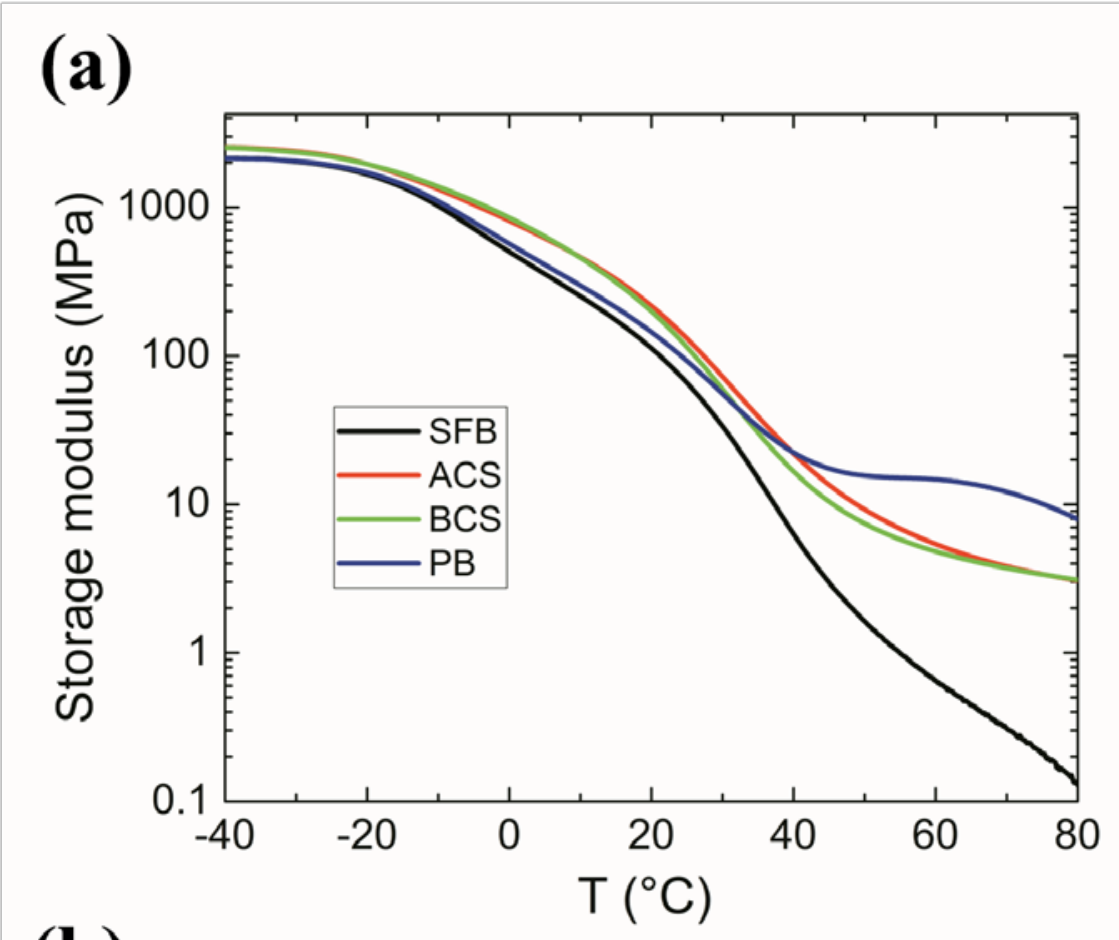

(b)

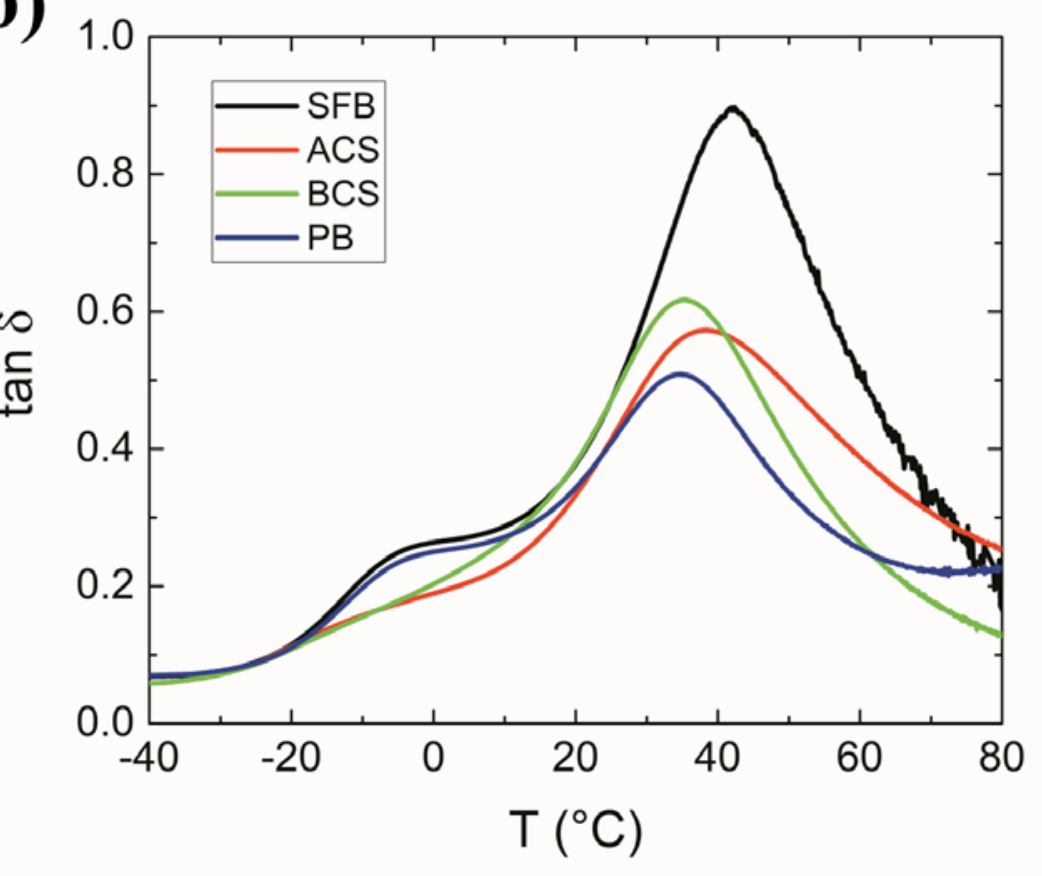

Figure 5. DMA curves as a function of temperature for the different materials investigated: (a) Storage modulus and (b) loss tangent ( $\tan \delta)$. 
Table 2. Physical properties of nanocomposites made from ceria Pickering latexes and physical blends

\begin{tabular}{|c|c|c|c|c|c|c|c|}
\hline Sample & $\mathrm{E}^{\prime}(\mathbf{M P a})^{\mathrm{a}}$ & $\begin{array}{c}\mathbf{T}_{\boldsymbol{a}} \\
\left({ }^{\circ} \mathbf{C}\right)^{\mathbf{b}}\end{array}$ & $\begin{array}{c}S_{200} \\
\left({ }^{\circ} \mathbf{C}\right)^{\mathrm{c}}\end{array}$ & $\begin{array}{c}\mu_{300} / \\
\boldsymbol{\mu}_{360} \\
\left(\mathbf{c m}^{-1}\right)^{\mathbf{d}}\end{array}$ & $\begin{array}{c}\boldsymbol{\mu}_{500} \\
\left(\mathbf{c m}^{-1}\right)^{d}\end{array}$ & $\begin{array}{c}\Delta \mathbf{H}_{\mathrm{f}} / \\
\Delta \mathbf{H}_{\mathbf{b}} \\
(\mathbf{J} / \mathbf{g})^{\mathrm{e}}\end{array}$ & $\begin{array}{l}\text { Water } \\
\text { uptake } \\
\text { (wt\%) }\end{array}$ \\
\hline SFB & 0.31 & 42 & 79 & $\begin{array}{c}80 \\
/ 62\end{array}$ & 50 & 1.22 & 14.0 \\
\hline ACS & 3.82 & 38 & 101 & $\begin{array}{l}1558 \\
/ 365\end{array}$ & 29 & 2.18 & 22.2 \\
\hline BCS & 3.72 & 35 & 122 & $\begin{array}{l}1349 \\
/ 821\end{array}$ & 247 & 4.4 & 12.2 \\
\hline PB & 12.10 & 35 & 86 & $\begin{array}{l}453 \\
/ 134\end{array}$ & 29 & 1.69 & 17.1 \\
\hline
\end{tabular}

a Storage modulus determined by DMA at $70{ }^{\circ} \mathrm{C}$. ${ }^{\mathrm{b}}$ Main relaxation temperature determined by the main peak position in tan $\delta$ measured by DMA. ${ }^{\mathrm{c}}$ Softening point determined by TMA. ${ }^{\mathrm{d}}$ Linear absorption coefficients at $300 \mathrm{~cm}^{-1}\left(\mu_{300}\right), 360 \mathrm{~cm}^{-1}\left(\mu_{360}\right)$ and $500 \mathrm{~cm}^{-1}\left(\mu_{500}\right)$ measured by UV-Vis spectroscopy. ${ }^{\text {e }}$ Ratio between heat of freezing of "free" $\left(\Delta H_{f}\right)$ and "bound" $\left(\Delta H_{b}\right)$ water measured by DSC.

In the softening point measurement, the specimens were compressed under a constant load (although there was also some shear stress as the probe penetrates) and temperature was increased to determine their upper service temperature. Whereas the DMA was performed on specimens under tension, the softening point measurements placed the specimen in compression. When a film is heated from a low temperature, thermal expansion is observed through a small increase in the thickness (a positive change in the dimension). As the temperature increases, the probe under a constant load penetrates into the specimen, as the modulus and viscosity decrease. ${ }^{53}$ The TMA curves are shown in Figure S5 (Supporting Information) up to the temperature at which the measurement becomes unstable. Values of the softening temperature, $S_{200}$, for the four samples are listed in Table 2. As a general trend, the BCS Pickering latex sample (with a higher amount of free ceria) shows the highest $S_{200}$ value. The lowest $S_{200}$ value is found for the blank latex as expected, because it will not have any reinforcement from the ceria. Free ceria nanoparticles are expected to enrich the top surface during film formation, and such enrichment of the surface could increase the structural stability at temperatures above the polymer's $T_{\mathrm{g}}$. 
An effective stress was calculated to be $20.1 \mathrm{kPa}$ from the load acting on the contact area of the probe. The strain of the specimen was estimated by dividing the dimensional change by the initial film thickness. An effective compressive relaxation modulus was found by dividing the stress by the strain, as the temperature was increased. Figure 6 shows stark differences between the three nanocomposites. Of the three, the BCS nanocomposite has the highest modulus at $70{ }^{\circ} \mathrm{C}$, whereas in tension at this same temperature, its storage modulus was the lowest of the three. In contrast, the PB nanocomposite had the highest storage modulus, but its relaxation modulus, found in compression, was the lowest (and comparable to the SFB polymer). The BCS nanocomposite has clusters of ceria nanoparticles distributed throughout it. Under compression, these clusters could be pushed into physical contact and thereby support a load. However, in tension, the load is supported by the continuous polymer phase, and there is little reinforcement, so the storage modulus is not increased significantly by the nanoceria. The nanoceria in the PB nanocomposite is not expected to be tightly bound to the polymer phase. The network of nanoceria in the cellular walls is not able to support a compressive stress. 


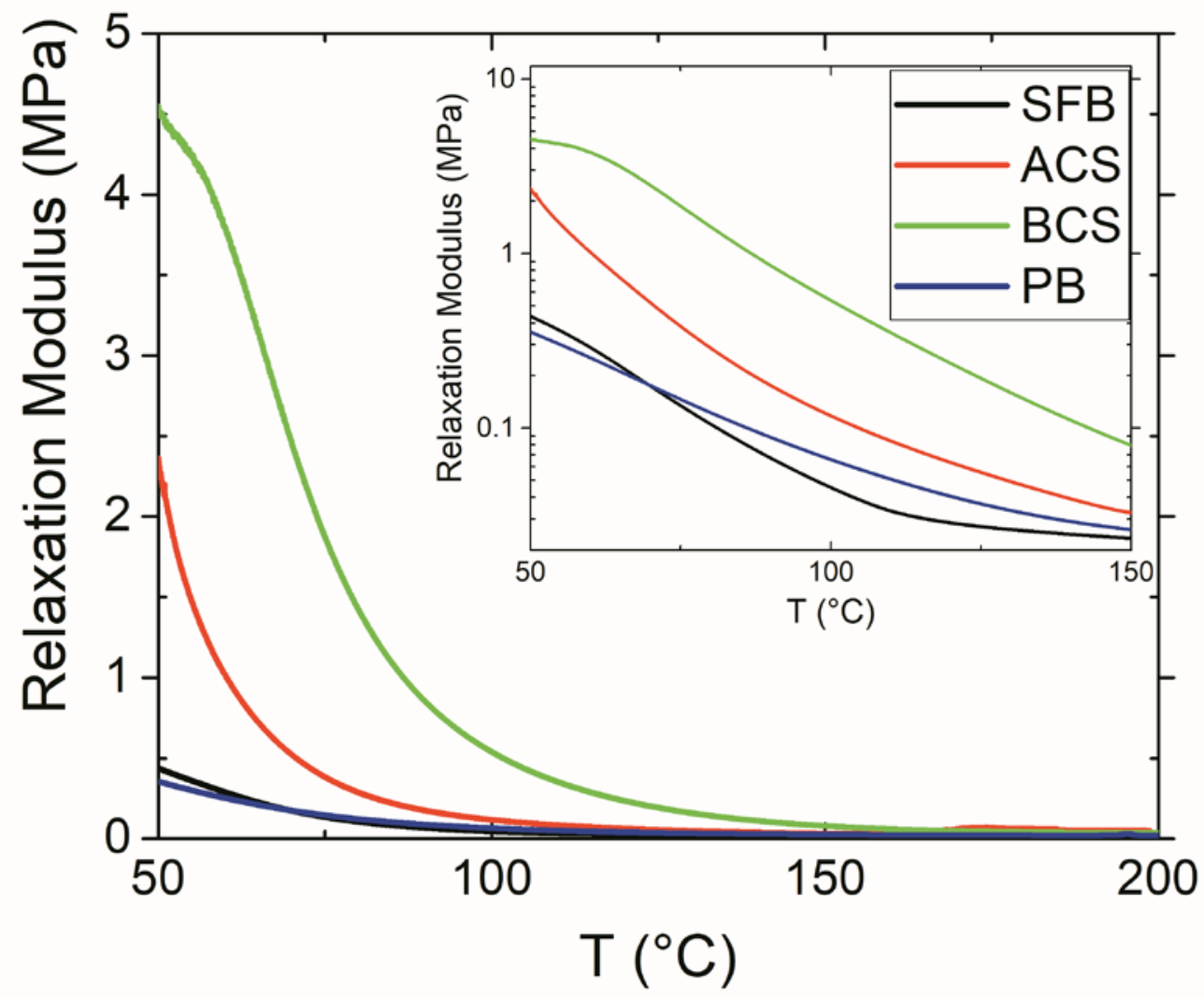

Figure 6. Effective relaxation modulus as a function of temperature for the three types of ceria Pickering nanocomposite and the blank polymer, as determined by TMA. Inset shows the data on a logarithmic scale.

\subsection{Optical properties and application as UV-absorbing coating}

For applications as coatings, optical properties are important. To protect the substrate and the polymer binder from UV degradation, it is beneficial to have a UV-absorbing filler. At the same time, for clear coatings, transparency in the visible region is required. It has been reported that the size of the inorganic fillers in polymer composites has a strong impact on their reflectance ${ }^{24}$ and transmittance, ${ }^{25}$ and this behavior is wavelength dependent. For hybrid ceria/acrylic latexes, size and aggregation of nanoceria are key factors in the final optical properties. ${ }^{54}$ The combination of UV absorption and optical transparency was therefore investigated for the ceria nanocomposites. 
The nanoceria (both in the acidic and basic ceria sol) has a strong UV absorption peak at approximately $210 \mathrm{~nm}$, and a weaker peak centered around $300 \mathrm{~nm}$ but extending up to $400 \mathrm{~nm}$. (See Figure S6 in Supporting Information.). The oxidation state of Ce has been reported to have a strong influence on the UV absorbance of ceria nanoparticles. When $\mathrm{Ce}^{4+}$ is predominant, the UV absorption is stronger than when a combination of $\mathrm{Ce}^{3+}$ and $\mathrm{Ce}^{4+}$ is present. ${ }^{55}$ To obtain information on the chemical state of the nanoceria, XPS analysis was performed. The Ce 3d core level XPS spectra of the two types of nanoparticles in the ceria sols are presented in Figure 7. The acidic ceria sol spectrum shows evidence for three spin-orbit-split doublets, as labelled on the figure, which are obtained only from the $4+$ oxidation state of Ce in the nanoparticles. ${ }^{56}$ The spectrum includes the characteristic $\mathrm{Ce}^{4+}$ peak for $3 \mathrm{~d}_{3 / 2}$ at $917 \mathrm{eV}$. The intensity of this characteristic peak is reduced for the basic ceria sol, indicating a reduction in the proportion of atoms in the $\mathrm{Ce}^{4+}$ state. Furthermore, the $\mathrm{Ce}^{4+}$ doublets are less distinct, suggesting the convolution of two doublets from the $\mathrm{Ce}^{3+}$ oxidation state, as has been reported previously for mixed cerium oxides. ${ }^{55,56}$ A likely explanation for the reduction from the $4+$ to the $3+$ state of cerium in the basic ceria sol is the transfer of an electron from oxygen atoms when citric acid bonds to the nanoceria surface.

The XPS spectra of the ACS and BCS nanocomposites correlate well to that of their corresponding ceria nanoparticles (see Figure S7 in Supporting Information). The polymerization process does not change the chemical states. Therefore, as primarily $\mathrm{Ce}^{4+}$ is present in the ACS nanocomposites, we expect a stronger UV absorption than in the BCS nanocomposite, which has evidence for the presence of some $\mathrm{Ce}^{3+}$. 


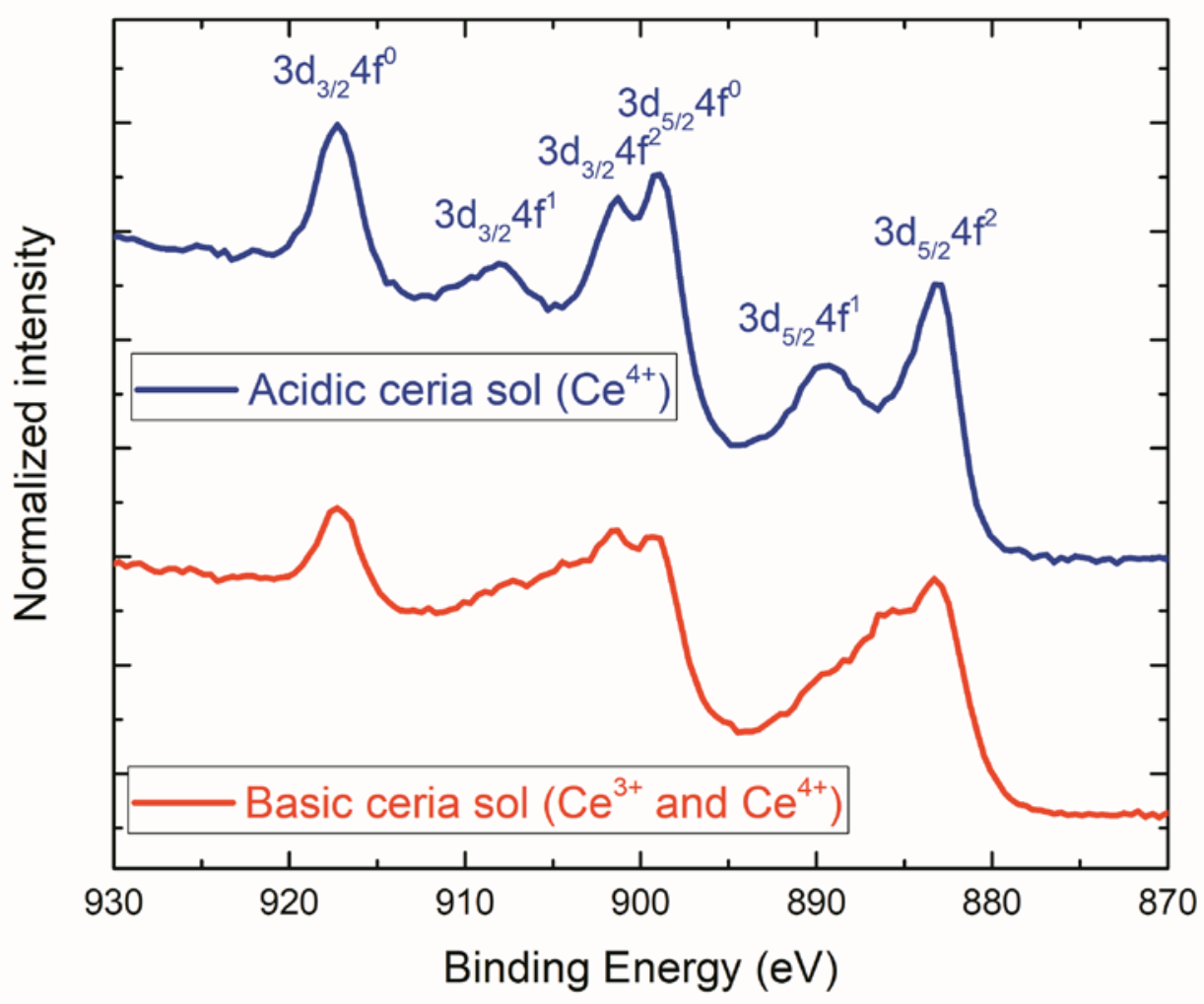

Figure 7. Ce 3d core level XPS spectra of the acidic and basic ceria sols after drying.

As is shown in Figure 8a, all latexes were film-forming and crack-free. The coatings containing ceria show a yellowish tint, which is much more intense for the BCS nanocomposite, which exhibits a noticeable loss of transparency. Crucially, the color is not uniform laterally in the BCS coating, and it is distinctly more yellow near the edges. When a colloidal dispersion is cast on a substrate with a contact angle, there is less water per unit area near the edge. The resulting concentration gradients drive a lateral flow of water from the center to the edge regions where there are packed particles. ${ }^{57}$ There is free nanoceria in the aqueous phase for the BCS Pickering latex (Figure 3b). When the latex particles pack at the film edge, the free nanoceria particles in the aqueous phase are expected to flow outward. Elsewhere it has been demonstrated that nanoparticles can be transported laterally through close-packed arrays of larger particles. ${ }^{58}$ The nanoceria with a diameter of $7 \mathrm{~nm}$ is much smaller than the size of the throats between the BCS particles that have a diameter of ca. $1 \mu \mathrm{m}$, which explains how the nanoceria can be transported to create the yellow edges in the 
coating. This lateral transport of the free nanoceria is detrimental for coatings applications. In contrast, the ACS nanocomposite, in which the nanoceria is bound to the latex particles and is not transported independently, exhibits uniformity in color. 

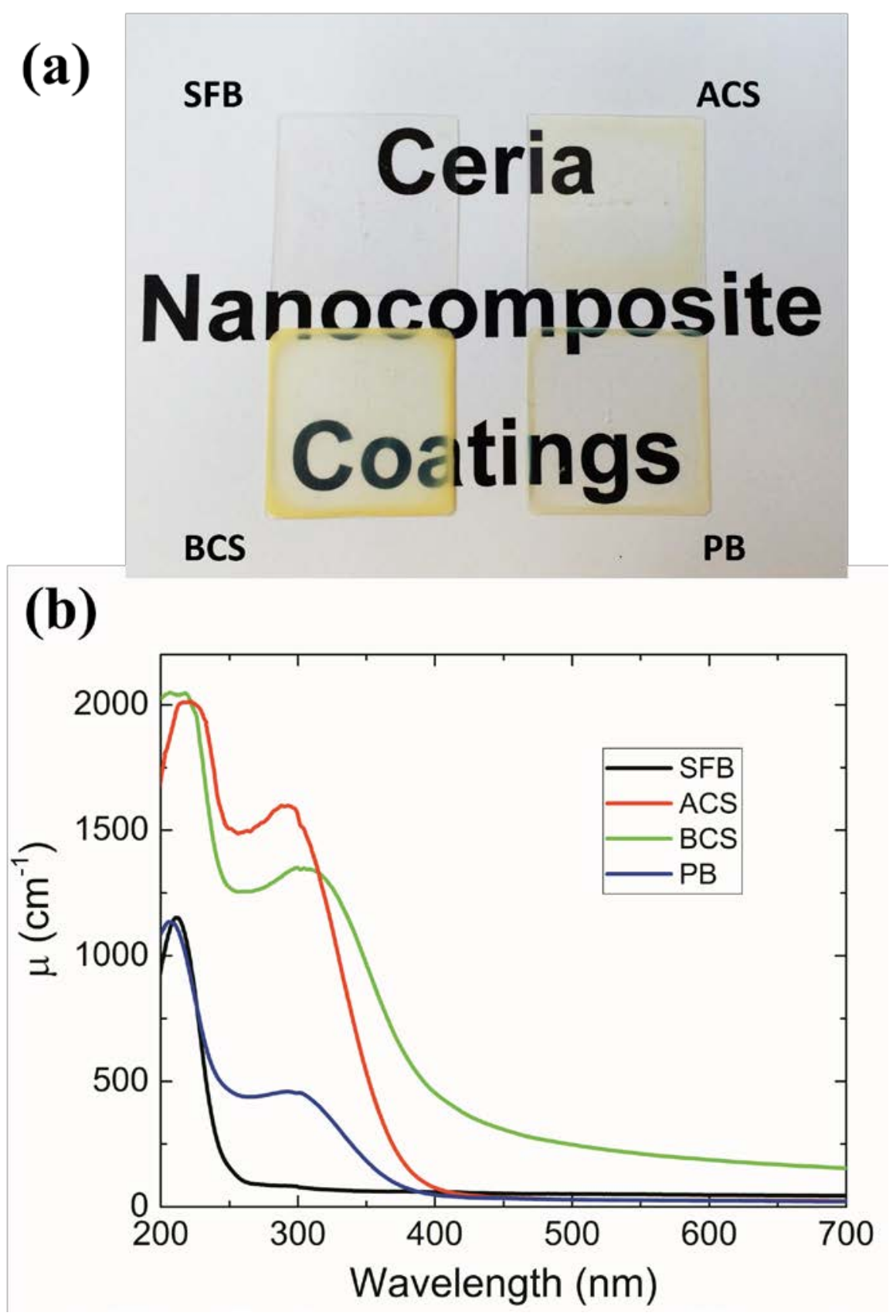

Figure 8. Optical properties of ceria nanocomposites: (a) Photographs of the different nanocomposite coatings on quartz substrates, and (b) linear absorption coefficients for ceria nanocomposites and the blank polymer as a function of the wavelength of the incident light. 
The linear absorption coefficient, $\mu$, of the nanocomposite films as a function of wavelength is presented in Figure 8. The absorption is the sum of effects of optical absorption and scattering. The blank (SFB) film shows a single peak around $230 \mathrm{~nm}$ which is attributed to absorption by polymer, which is expected to contribute to the extinction in the nanocomposites. The spectra from the three ceria nanocomposites show a second peak around $300 \mathrm{~nm}$, which is in the same position as the absorption band of the nanoceria sol. Table 2 lists the values of $\mu$ for three representative wavelength ranges: UVB $(\lambda=300 \mathrm{~nm})$, UVA $(\lambda=360 \mathrm{~nm})$ and visible $(\lambda=500 \mathrm{~nm})$. The latter was chosen in order to evaluate transparency, and the first and second were chosen to assess the potential for providing UV protection. The UVC range is not considered here because it is largely absorbed by the ozone layer in the atmosphere. ${ }^{59}$

With the incorporation of nanoceria, the absorption in the Pickering nanocomposites (ACS and BCS) in the UV range is up to 20 times higher with respect to that of the blank (SFB). The absorption peak near $300 \mathrm{~nm}$ is attributed to the nanoceria absorption, as it is also found in the absorbance spectrum of the nanoceria sol. This peak is stronger for the ACS nanocomposite, as it contains primarily $\mathrm{Ce}^{4+}$ according to the XPS analysis (Figure S7a), whereas there is evidence from XPS for the presence of the $\mathrm{Ce}^{3+}$ oxidation state in the BCS nanocomposite (Figure S7b). The peak at approximately $220 \mathrm{~nm}$ is attributed to a combination of the polymer absorption and the nanoceria absorption. In contrast, in PB, there is a comparatively weak extinction peak at $300 \mathrm{~nm}$, and the peak near $200 \mathrm{~nm}$ is comparable to what is found for the polymer phase. The nanoceria content of PB is slightly lower than that of ACS or BCS, which might contribute to its weaker absorbance.

In the BCS Pickering nanocomposite, there is an increase in the extinction in the visible range, which explains its yellowish tint. The extinction of the BCS nanocomposite in the visible range can be attributed to the structure shown in Figure 4b. The excess ceria is found in clusters between the polymer particles, with a size ranging from hundreds of $\mathrm{nm}$ up to several $\mu \mathrm{m}$, as is estimated from FIB-SEM images (Figure 4). This size of ceria clusters is large enough to scatter light, particularly at shorter wavelengths, leading to an increase in $\mu$ with decreasing wavelength. In the ACS Pickering 
nanocomposite, the ceria nanoparticles decorate the particle boundaries, but they do not cluster in larger structures that scatter light.

Notably, because of the observed lateral transport of the ceria to the coating edges, the average nanoceria concentration at the center of the BCS coating should be lower than in the ACS coating. Nevertheless, the ACS coating shows negligible extinction in the visible region (above 400 $\mathrm{nm}$ ) coupled with the strongest extinction in the UV region. Hence, the ACS nanocomposite has the ideal optical properties for a clear barrier coating with UV absorption, and it offers benefits that neither the PB nor the BCS can offer.

Although both the optical and the mechanical properties depend on the nanostructures of the materials and hence might have some correlation, it is not straightforward to attempt to correlate them in the present experiments because of a large number of other variables. For instance, the amount of auxiliary comonomer (MAA) that is used for the BCS latex is much higher, resulting in films with a storage modulus which is comparable to that of ACS films (although the structure is less mechanically stable due to the presence of aggregates). Therefore, a fair correlation between the mechanical properties and UV absorption of ACS and BCS films cannot be made. Also, when drying films for optical testing, the free ceria tends to accumulate at the edges due to outward flow of water to the thinner region at the edge, resulting in the same microstructure but a different ceria distribution than in films dried in a mould for mechanical properties testing.

As the nanocomposites present significant absorbance in the UV, they should provide protection against UV degradation when applied on a substrate. To test their application as UVabsorbing coatings, coloured poly(chloroprene) rubber substrates were coated by drop-casting of the different latex dispersions followed by exposure to UV light for 60 minutes inside a UV/ozone chamber (Bioforce Nanosciences, model UV.TC.EU.003). Half of the sample was masked to provide a reference of the initial, non-irradiated sample. Results are shown in Figure 9 and Figure S8 (profiles of the contrast laterally across the coating). The exposed rubber, without a coating, became noticeably darker in color. The uncoated substrate presented an optical contrast between the exposed and masked areas of around 35\% (estimated using ImageJ analysis software) and, although the SFB and BCS 
coatings presented partial UV protection (ca. 10\% contrast), the ACS coatings prevent fully the bleaching and fading of the substrate. This experiment demonstrates the potential of the ACS dispersion in UV-protective coatings applications.

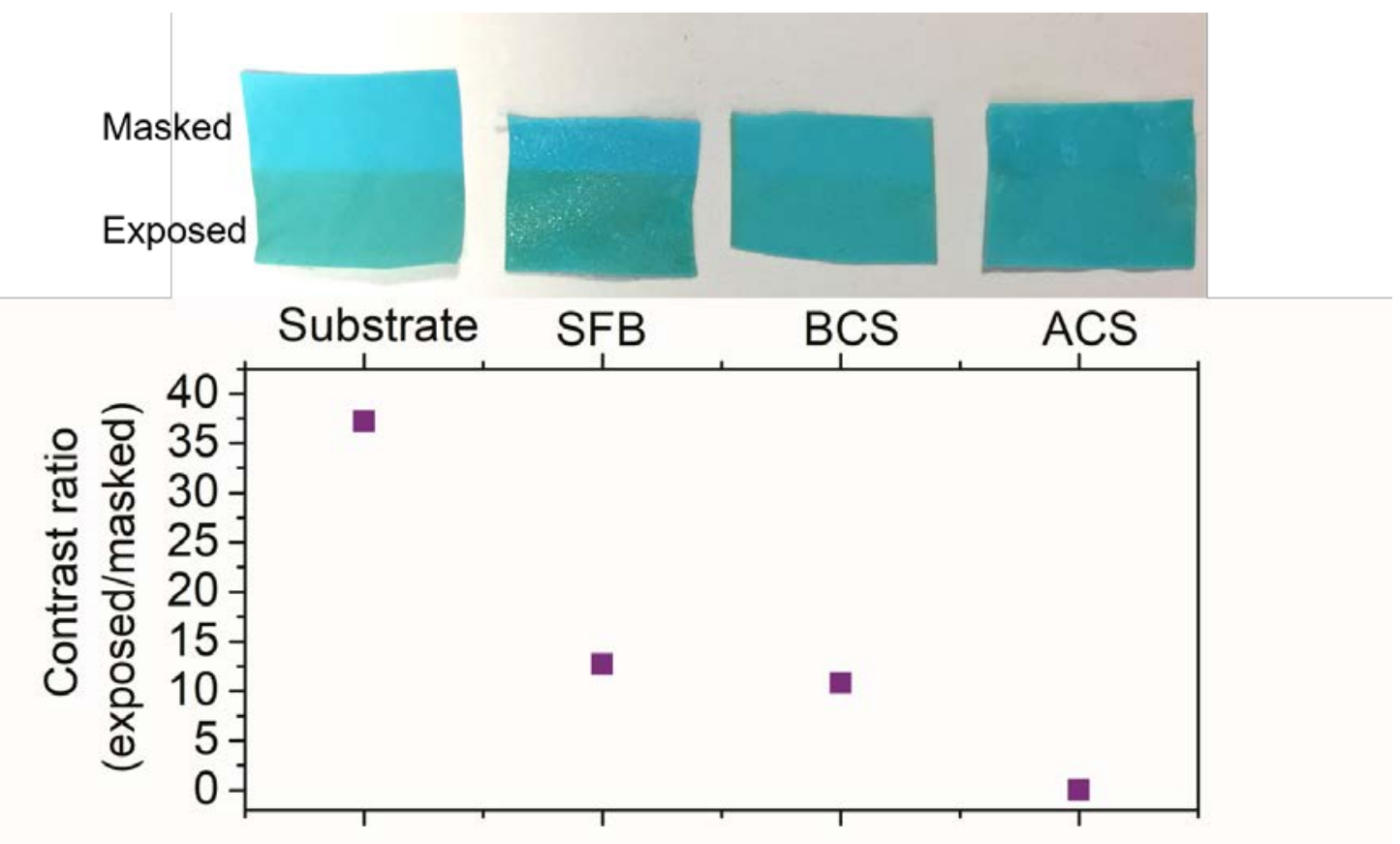

Figure 9. UV degradation study of coloured rubber substrates coated with different ceria nanocomposites. Top: Images of the samples after irradiation. Below: optical contrast ratio between the exposed/masked areas of the substrate, which is used as a measure of UV bleaching.

\subsection{Water barrier properties}

As was already noted in the experimental section, the synthesis of all the latexes is surfactantfree. The absence of these amphiphilic short chain molecules might reduce the detrimental impact that they usually have on the water barrier properties of latex films. ${ }^{60,61}$ As a benchmark comparison, the introduction of an inert inorganic phase into a continuous polymer phase in a composite is expected to reduce the total water solubility per unit volume, because of the reduction in the volume fraction of the polymer phase. ${ }^{62}$ 
To evaluate the barrier property of the nanocomposites when exposed to liquid water, DSC analysis was used to estimate the amount of sorbed water and also to provide information on the state of the water: whether "bound" or "free". ${ }^{63}$ The DSC cooling and heating traces from samples immersed for three days in deionized water are shown in Figure 9a and b, respectively.

During cooling two exothermic freezing peaks were detected (Figure 10a), associated with different water environments. The first peak, around $-20^{\circ} \mathrm{C}$, can be attributed to the freezing of water within the particles that is unassociated with the polymer and to any remaining bulk water outside the particles. In contrast, the second peak (around $-45^{\circ} \mathrm{C}$ ) is related to freezable bound water, which is described to be the secondary sheath of water molecules weakly bound to the water molecules that are strongly bound to the polymer. ${ }^{64}$ These strongly bound water molecules are non-freezable, and the only way to detect them by DSC is by measuring the glass transition shift (i.e. plasticization). ${ }^{65,66}$ The glass transition temperature of the copolymer overlaps with the water melting peak, and therefore it is difficult to separate. Hence, the plasticization of the polymer phase could not be measured. The ratio between the heat of freezing of "free" $\left(\Delta H_{\mathrm{f}}\right)$ and "bound" $\left(\Delta H_{\mathrm{b}}\right)$ water (Table 2) provides an indication of the distribution of water within the film. In the blank polymer (SFB), the data indicate that the water is distributed approximately equally between the bound and free states. The introduction of ceria increases the amount of free water in ACS and PB, which becomes larger with larger ceria clusters in the BCS Pickering nanocomposite.

Upon heating the water-soaked specimens (Figure 10b), a broad endothermic peak, centred around $5{ }^{\circ} \mathrm{C}$ and attributed to ice melting, is detected for all nanocomposites. The area under this peak gives the heat of fusion of the frozen water contained in the sample, in $\mathrm{J} \mathrm{g}^{-1}$. By dividing this value by the heat of fusion of water $\left(333.5 \mathrm{~J} \mathrm{~g}^{-1}\right)^{67}$ the weight percentage of freezable water in the sample can be calculated. These values are shown in Table 2 for each of the nanocomposites. All three nanocomposites show an additional small sharp peak near $0{ }^{\circ} \mathrm{C}$ that is not present in the curve for the blank (SFB). This peak corresponds to very mobile clusters of water, probably located in between $\mathrm{CeO}_{2}$ nanoparticles, that are not hydrogen bonded to a surface. The absence of this peak in the blank latex indicates a good degree of coalescence and essentially full elimination of the voids that would 
otherwise lead to water reservoirs upon immersion. In terms of total water content, the BCS nanocomposite has a similar value compared to the SFB (12.2 wt.\% and $14.0 \mathrm{wt} \%$ respectively, see Table 2). In the BCS nanocomposite, the nanoceria comprises an estimated $17 \%$ by volume (because it is denser than the polymer phase). Hence, the observed reduction of water sorption is lower than what is expected from the introduction of an inert filler. This result indicates that the voids between the nanoceria in the clusters are counter-acting the effect of the filler. However, because the nanoceria does not block all of the interfaces between the polymer particles (as shown in Figure 3b), there is a continuous polymer phase that provides some barrier to water transport. Although this amount of water sorption might seem at first to be high, it is comparable to the amount reported elsewhere ${ }^{68}$ to be absorbed by surfactant-free latex films after one day of water immersion. In contrast, waterborne acrylic films containing surfactant have been reported to absorb $100 \%$ of their mass after only 100 min of water immersion. ${ }^{61}$

In the ACS Pickering and PB nanocomposites, there is an even higher sorbed water content (17.1 wt\% and $22 \mathrm{wt} \%$, respectively). In these materials, the ceria nanoparticles surround each of the polymer particles to make a continuous path in the honeycomb structure. This path could assist the transport of water. Although the BCS Pickering film contains ceria in clusters, these clusters do not form a continuous path and - according to the microscopy analysis - are embedded in a coalesced film. These results show the detrimental effect of the presence of ceria nanoparticles at the particle boundaries in the ACS Pickering films. 


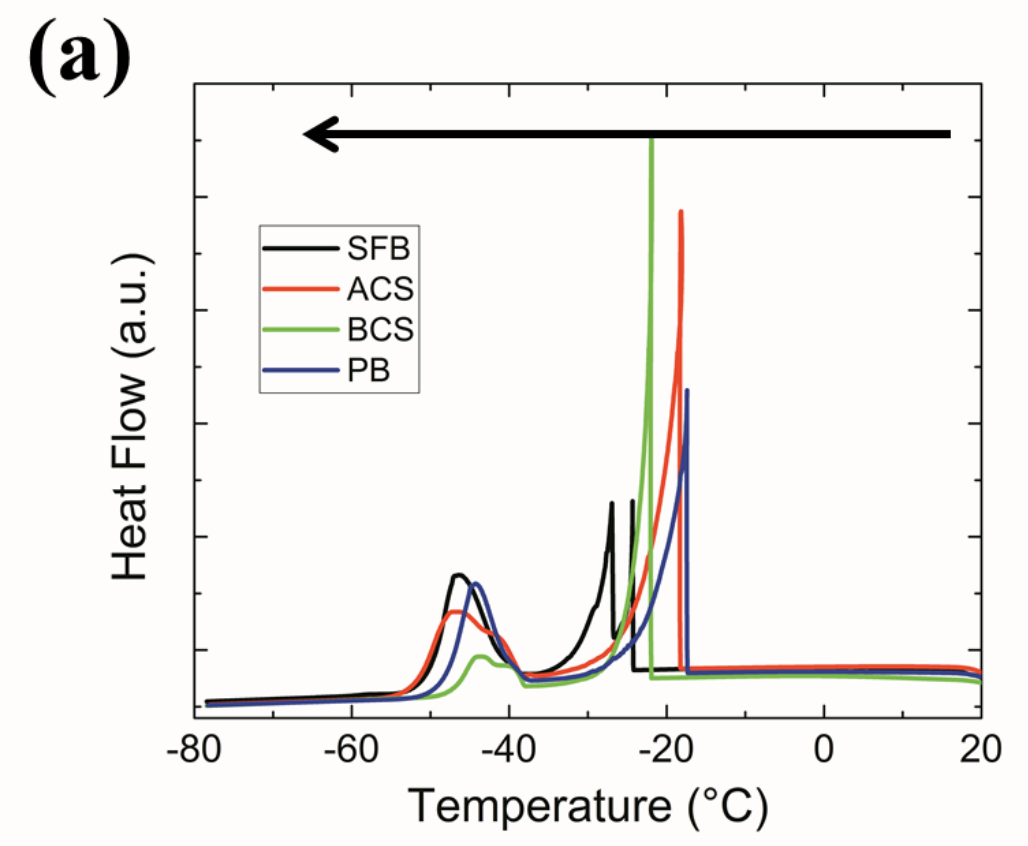

\section{(b)}

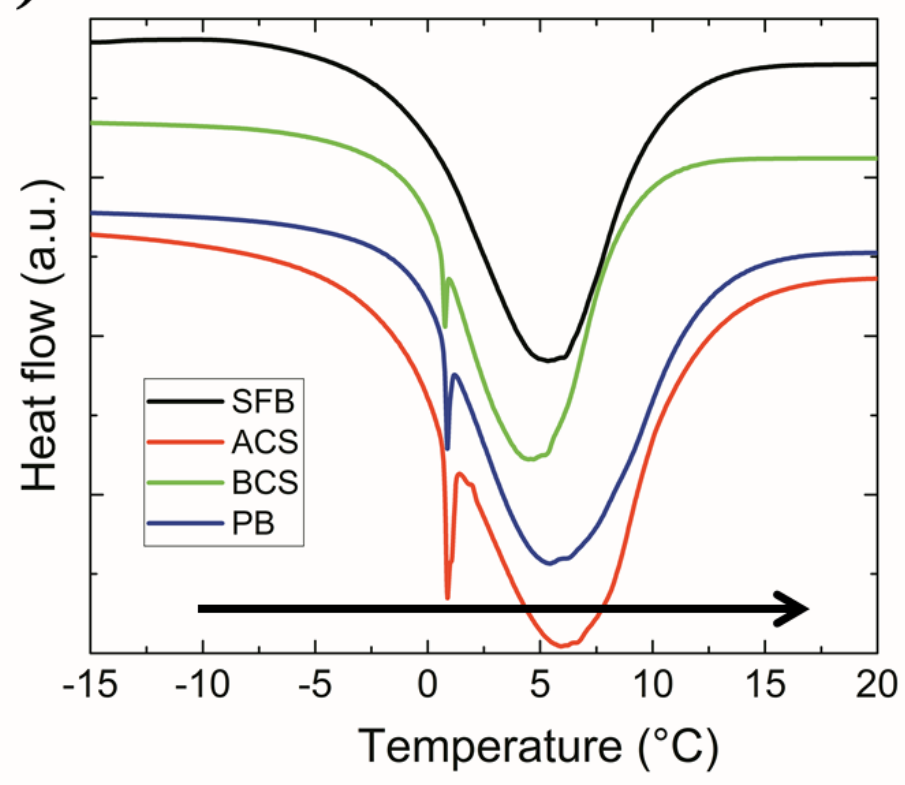

Figure 10. Thermal analysis of specimens after soaking for three days in deionized water, as determined during (a) cooling and (b) heating cycles.

\section{Conclusions}

We have designed and fabricated polymer/nanoceria nanocomposites using both high-solids Pickering particle dispersions and the physical blending of surfactant-free polymer particles (of the same composition) with a nanoceria sol. According to electron microscopy characterization, the films cast 
from the acidic sol Pickering particles and from the physical blend with nanoceria both show ceria in a honeycomb structure, wherein every polymer particle is surrounded by ceria nanoparticles. In the physical blend, the interaction of the MAA units in the blank latex with the nanoceria builds a shell layer around the particles. The basic sol Pickering latex contains some free nanoceria in the aqueous phase, and the resulting films show large ceria clusters at particle interfaces. Our results show that the resulting coating properties are strongly defined by these various nanoceria distributions.

The honeycomb structure formed by the ACS Pickering particles retains the high transparency of the original polymer, unlike the BCS nanocomposite which contains aggregates that confers a yellow appearance to the film. A lower water uptake is attributed to the presence of nanoceria clusters in a coalesced polymer phase in comparison to the blank polymer. In compression, the jamming of the nanoceria clusters leads to a higher effective modulus and softening point, but in tension the storage modulus is not as high with this structure in comparison to the honeycomb structure.

The results presented here provide a valuable guide to determine which nanocomposite fabrication route should be chosen depending on the final properties that are needed. The acidic sol Pickering nanocomposite (honeycomb structure) shows the best combination of high absorbance in the UV region (attributed to a very high proportion of $\mathrm{Ce}^{4+}$ ) and high visible transmittance for UVresistant, clear coating applications. A coloured rubber substrate coated with this nanocomposite coating did not fade or bleach after intense UV irradiation for an hour, proving the potential of this material for UV protective coating applications. The BCS Pickering nanocomposite (with nanoceria aggregates) is a better candidate for corrosion protection coatings, which demand the elimination of any continuous hydrophilic path.

\section{SUPPORTING INFORMATION}

Correlograms obtained from dynamic light scattering; Atomic force microscopy of ACS and BCS Pickering particles; Thermogravimetric analysis of the blank latex, the physical blend and the ceria stabilized latexes; Dimensional change as a function of temperature for the three types of ceria 
Pickering nanocomposites; Absorbance spectra obtained for the acidic and basic ceria sol; XPS analysis of ACS and BCS nanocomposite films; Optical micrographs of the unmasked and masked regions of the rubber substrate after UV irradiation coated with different latexes

\section{AUTHOR INFORMATION}

\section{Corresponding Author}

*i.martin-fabiani@lboro.ac.uk

\section{Acknowledgements}

The authors acknowledge funding from the European Union Seventh Framework Programme BARRIER-PLUS project (FP7-SME-2012-2, no. 304758). Technical support from Violeta Doukova is also gratefully acknowledged. We benefitted from useful discussions with James Adams and Marian Florescu (University of Surrey). The authors are indebted to the "Microstructure Technological Center” (CT $\mu$ ), platform of the Université Claude Bernard, Lyon 1 (Villeurbanne, France) for the access to the transmission electron microscope and the cryo-ultramicrotome. 


\section{References}

(1) Reed, K.; Cormack, A.; Kulkarni, A.; Mayton, M.; Sayle, D.; Klaessig, F.; Stadler, B.

Exploring the Properties and Applications of Nanoceria: Is There Still Plenty of Room at the Bottom? Environ. Sci. Nano 2014, 1, 390-405.

(2) Trovarelli, A. Catalytic Properties of Ceria and CeO2-Containing Materials. Catal. Rev. 1996, 38, 439-520.

(3) Lin, Y.; Wu, Z.; Wen, J.; Poeppelmeier, K. R.; Marks, L. D. Imaging the Atomic Surface Structures of CeO2 Nanoparticles. Nano Lett. 2014, 14, 191-196.

(4) Eranna, G.; Joshi, B. C.; Runthala, D. P.; Gupta, R. P. Oxide Materials for Development of Integrated Gas Sensors - A Comprehensive Review. Crit. Rev. Solid State Mater. Sci. 2004, 29, 111-188.

(5) Jasinski, P.; Suzuki, T.; Anderson, H. U. Nanocrystalline Undoped Ceria Oxygen Sensor. Sensors Actuators, B Chem. 2003, 95, 73-77.

(6) Dou, B.; Lv, G.; Wang, C.; Hao, Q.; Hui, K. S. Cerium Doped Copper/ZSM-5 Catalysts Used for the Selective Catalytic Reduction of Nitrogen Oxide with Ammonia. Chem. Eng. J. 2015, 270, 549-556.

(7) Mari, M.; Müller, B.; Landfester, K.; Muñoz-Espí, R. Ceria/Polymer Hybrid Nanoparticles as Efficient Catalysts for the Hydration of Nitriles to Amides. ACS Appl. Mater. Interfaces. 2015, 7, 10727-10733.

(8) Corma, A.; Atienzar, P.; Garcia, H.; Chane-Ching, J.-Y. Hierarchically Mesostructured Doped CeO2 with Potential for Solar-Cell Use. Nat Mater. 2004, 3, 394-397.

(9) Lira-Cantu, M.; Krebs, F. C. Hybrid Solar Cells Based on MEH-PPV and Thin Film Semiconductor Oxides (TiO2, Nb2O5, ZnO, CeO2 and CeO2-TiO2): Performance Improvement during Long-Time Irradiation. Sol. Energy Mater. Sol. Cells 2006, 90, 2076- 
2086.

(10) Yabe, S.; Sato, T. Cerium Oxide for Sunscreen Cosmetics. J. Solid State Chem. 2003, 171, 711.

(11) Ecco, L. G.; Fedel, M.; Ahniyaz, A.; Deflorian, F. Influence of Polyaniline and Cerium Oxide Nanoparticles on the Corrosion Protection Properties of Alkyd Coating. Prog. Org. Coatings. 2014, 77, 2031-2038.

(12) Aguirre, M.; Johansson Salazar-Sandoval, E.; Johansson, M.; Ahniyaz, A.; Paulis, M.; Leiza, J. R. Hybrid Acrylic/CeO ${ }_{2}$ Nanocomposites Using Hydrophilic High Aspect Ratio $\mathrm{CeO}_{2}$ Nanoparticles. J. Mater. Chem. A 2014, 2, 20280-20287.

(13) Aguirre, M.; Paulis, M.; Leiza, J. R. UV Screening Clear Coats Based on Encapsulated $\mathrm{CeO}_{2}$ Hybrid Latexes. J. Mater. Chem. A 2013, 1, 3155-3162.

(14) Gao, H.; Qiao, B.; Wang, T.; Wang, D.; Jin, Y. Cerium Oxide Coating of Titanium Dioxide Pigment to Decrease Its Photocatalytic Activity. Ind. Eng. Chem. Res. 2014, 53, 189-197.

(15) Liu, F.; Bai, L.; Zhang, H.; Song, H.; Hu, L.; Wu, Y.; Ba, X. Smart H2O2-Responsive Drug Delivery System Made by Halloysite Nanotubes and Carbohydrate Polymers. ACS Appl. Mater. Interfaces. 2017, 9, 31626-31633.

(16) Zhang, H.; Ren, T.; Ji, Y.; Han, L.; Wu, Y.; Song, H.; Bai, L.; Ba, X. Selective Modification of Halloysite Nanotubes with 1-Pyrenylboronic Acid: A Novel Fluorescence Probe with Highly Selective and Sensitive Response to Hyperoxide. ACS Appl. Mater. Interfaces. 2015, 7, 23805-23811.

(17) Wang, T.; Keddie, J. L. Design and Fabrication of Colloidal Polymer Nanocomposites. Adv. Colloid Interface Sci. 2009, 147-148, 319-332.

(18) Noël, A.; Faucheu, J.; Chenal, J. M.; Viricelle, J. P.; Bourgeat-Lami, E. Electrical and Mechanical Percolation in Graphene-Latex Nanocomposites. Polymer. 2014, 55, 5140-5145. 
(19) Kyrylyuk, A. V; Hermant, M. C.; Schilling, T.; Klumperman, B.; Koning, C. E.; van der Schoot, P. Controlling Electrical Percolation in Multicomponent Carbon Nanotube Dispersions. Nat. Nanotechnol. 2011, 6, 364-369.

(20) Kotal, M.; Bhowmick, A. K. Polymer Nanocomposites from Modified Clays: Recent Advances and Challenges. Prog. Polym. Sci. 2015, 51, 127-187.

(21) Buss, F.; Roberts, C. C.; Crawford, K. S.; Peters, K.; Francis, L. F. Effect of Soluble Polymer Binder on Particle Distribution in a Drying Particulate Coating. J. Colloid Interface Sci. 2011, 359, 112-120.

(22) Luo, H.; Cardinal, C. M.; Scriven, L. E.; Francis, L. F.; January, R. V; Re, V.; Recei, M.; February, V. Ceramic Nanoparticle / Monodisperse Latex Coatings. 2008, 24, 335-339.

(23) Bleach, N. C.; Nazhat, S. N.; Tanner, K. E.; Kellomäki, M.; Törmälä, P. Effect of Filler Content on Mechanical and Dynamic Mechanical Properties of Particulate Biphasic Calcium Phosphate--Polylactide Composites. Biomaterials. 2002, 23, 1579-1585.

(24) Sun, J.; Velamakanni, B. V.; Gerberich, W. W.; Francis, L. F. Aqueous Latex/Ceramic Nanoparticle Dispersions: Colloidal Stability and Coating Properties. J. Colloid Interface Sci. 2004, 280, 387-399.

(25) Tzitzinou, A.; Keddie, J. L.; Geurts, J. M.; Peters, A. C. I. A.; Satguru, R. Film Formation of Latex Blends with Bimodal Particle Size Distributions: Consideration of Particle Deformability and Continuity of the Dispersed Phase. Macromolecules. 2000, 33, 2695-2708.

(26) Brunier, B.; Sheibat-Othman, N.; Chniguir, M.; Chevalier, Y.; Bourgeat-Lami, E. Investigation of Four Different Laponite Clays as Stabilizers in Pickering Emulsion Polymerization. Langmuir. 2016, 32, 6046-6057.

(27) Delafresnaye, L.; Dugas, P.-Y.; Dufils, P.-E.; Chaduc, I.; Vinas, J.; Lansalot, M.; BourgeatLami, E. Synthesis of Clay-Armored Poly(Vinylidene Chloride-Co-Methyl Acrylate) Latexes by Pickering Emulsion Polymerization and Their Film-Forming Properties. Polym. Chem. 
2017, 8, 6127-6232.

(28) Balmer, J. A.; Schmid, A.; Armes, S. P. Colloidal Nanocomposite Particles: Quo Vadis? J. Mater. Chem. 2008, 18, 5722-5730.

(29) Lotierzo, A.; Bon, S. A. F. A Mechanistic Investigation of Pickering Emulsion Polymerization. Polym. Chem. 2017, 8, 5100-5111.

(30) Zgheib, N.; Putaux, J. L.; Thill, A.; D’Agosto, F.; Lansalot, M.; Bourgeat-Lami, E. Stabilization of Miniemulsion Droplets by Cerium Oxide Nanoparticles: A Step toward the Elaboration of Armored Composite Latexes. Langmuir. 2012, 28, 6163-6174.

(31) González, E.; Bonnefond, A.; Barrado, M.; Casado Barrasa, A. M.; Asua, J. M.; Leiza, J. R. Photoactive Self-Cleaning Polymer Coatings by $\mathrm{TiO}_{2}$ Nanoparticle Pickering Miniemulsion Polymerization. Chem. Eng. J. 2015, 281, 209-217.

(32) González-Matheus, K.; Leal, G. P.; Asua, J. M. Film Formation from Pickering Stabilized Waterborne Polymer Dispersions. Polymer. 2015, 69, 73-82.

(33) Gao, D.; Liang, Z.; Lyu, B.; Feng, J.; Ma, J.; Wei, Q. “Soft” Polymer Latexes Stabilized by a Mixture of Zinc Oxide Nanoparticles and Polymerizable Surfactants: Binders for Pigment Printing. Prog. Org. Coatings. 2016, 101, 262-269.

(34) Wang, T.; Colver, P. J.; Bon, S. A. F.; Keddie, J. L. Soft Polymer and Nano-Clay Supracolloidal Particles in Adhesives: Synergistic Effects on Mechanical Properties. Soft Matter. 2009, 5, 3842-3849.

(35) Warnant, J.; Garnier, J.; van Herk, A.; Dufils, P.-E.; Vinas, J.; Lacroix-Desmazes, P. A CeO2/PVDC Hybrid Latex Mediated by a Phosphonated Macro-RAFT Agent. Polym. Chem. 2013, 4, 5656-5663.

(36) Zgheib, N.; Putaux, J.-L.; Thill, A.; Bourgeat-Lami, E.; D’Agosto, F.; Lansalot, M. Cerium Oxide Encapsulation by Emulsion Polymerization Using Hydrophilic MacroRAFT Agents. Polym. Chem. 2013, 4, 607-614. 
(37) De San Luis, A.; Paulis, M.; Leiza, J. R. Co-Encapsulation of CdSe/ZnS and $\mathrm{CeO}_{2}$ Nanoparticles in Waterborne Polymer Dispersions: Enhancement of Fluorescence Emission under Sunlight. Soft Matter. 2017, 13, 8039-8047.

(38) Olsson, S. K.; Johansson, M.; Westin, M.; Östmark, E. Reactive UV-Absorber and Epoxy Functionalized Soybean Oil for Enhanced UV-Protection of Clear Coated Wood. Polym. Degrad. Stab. 2014, 110, 405-414.

(39) Choo, D. C.; Kim, T. W. Degradation Mechanisms of Silver Nanowire Electrodes under Ultraviolet Irradiation and Heat Treatment. Sci. Rep. 2017, 7, 1-12.

(40) Bourgeat-Lami, E.; Guimarães, T. R.; Pereira, A. M. C.; Alves, G. M.; Moreira, J. C.; Putaux, J. L.; Dos Santos, A. M. High Solids Content, Soap-Free, Film-Forming Latexes Stabilized by Laponite Clay Platelets. Macromol. Rapid Commun. 2010, 31, 1874-1880.

(41) Sheibat-Othman, N.; Bourgeat-Lami, E. Use of Silica Particles for the Formation of OrganicInorganic Particles by Surfactant-Free Emulsion Polymerization. Langmuir. 2009, 25, 1012110133.

(42) Percy, M. J.; Barthet, C.; Lobb, J. C.; Khan, M. A.; Lascelles, S. F.; Vamvakaki, M.; Armes, S. P.; Bn, B. Synthesis and Characterization of Vinyl Polymer - Silica Colloidal Nanocomposites. Langmuir. 2000, 16, 6913-6920.

(43) Li, K.; Dugas, P. Y.; Lansalot, M.; Bourgeat-Lami, E. Surfactant-Free Emulsion Polymerization Stabilized by Ultrasmall Superparamagnetic Iron Oxide Particles Using Acrylic Acid or Methacrylic Acid as Auxiliary Comonomers. Macromolecules. 2016, 49, 7609-7624.

(44) Zgheib, N. Élaboration de Particules de Latex Composites à Base d'oxyde de Cérium Par Polymérisation Radicalaire En Milieu Aqueux Dispersé, University Lyon 1, 2011.

(45) Dehan, V.; Bourgeat-Lami, E.; D’Agosto, F.; Duffy, B.; Fortini, A.; Hilton, S.; Krassa, K.; Keddie, J. L.; Koh, M. L.; Lansalot, M.; Lee, M.; Lesage de la Haye, J.; Martin-Fabiani, I.; 
Mantzaridis, C.; Mazeffa, D. P.; Sear, R. P.; Schulz, M.; Sibbald, M.; Skerry, B.; Thomas, B. High-Performance Water-Based Barrier Coatings for the Corrosion Protection of Structural Steel. Steel Constr. 2017, 10, 254-259.

(46) Kobayashi, M.; Rharbi, Y.; Brauge, L.; Cao, L.; Winnik, M. A. Effect of Silica as Fillers on Polymer Interdiffusion in Poly(Butyl Methacrylate) Latex Films. Macromolecules. 2002, 35, 7387-7399.

(47) Zhu, J.; Morgan, A. B.; Lamelas, F. J.; Wilkie, C. A. Fire Properties of Polystyrene-Clay Nanocomposites. Chem. Mater. 2001, 13, 3774-3780.

(48) Kashiwagi, T.; Morgan, A. B.; Antonucci, J. M.; VanLandingham, M. R.; Harris, R. H.; Awad, W. H.; Shields, J. R. Thermal and Flammability Properties of a SilicaPoly(Methylmethacrylate) Nanocomposite. J. Appl. Polym. Sci. 2003, 89, 2072-2078.

(49) Faucheu, J.; Gauthier, C.; Chazeau, L.; Cavaillé, J. Y.; Mellon, V.; Pardal, F.; Lami, E. B. Properties of Polymer/Clay Interphase in Nanoparticles Synthesized through in-Situ Polymerization Processes. Polymer. 2010, 51, 4462-4471.

(50) Wang, T.; Lei, C. H.; Dalton, A. B.; Creton, C.; Lin, Y.; Fernando, K. A. S.; Sun, Y. P.; Manea, M.; Asua, J. M.; Keddie, J. L. Waterborne, Nanocomposite Pressure-Sensitive Adhesives with High Tack Energy, Optical Transparency, and Electrical Conductivity. Adv. Mater. 2006, 18, 2730-2734.

(51) Rajatapiti, P.; Dimonie, V. L.; El-Aasser, M. S.; Vratsanos, M. S. Effects of Compatibilizing Agents in Poly(n-Butyl Acrylate)/Poly(Methyl Methacrylate) Composite Latexes. J. Appl. Polym. Sci. 1997, 63, 205-219.

(52) Koh, A. Y. C.; Mange, S.; Bothe, M.; Leyrer, R. J.; Gilbert, R. G. The Influence of Copolymerization with Methacrylic Acid on Poly(Butyl Acrylate) Film Properties. Polymer. 2006, 47, 1159-1165.

(53) Wicks, Z. W.; Jones, F. N.; Pappas, S. P.; Wicks, D. A. Mechanical Properties. In Organic 
coatings; John Wiley \& Sons: Hoboken, New Jersey, 2006; pp 68-96.

(54) Aguirre, M.; Paulis, M.; Leiza, J. R. Particle Nucleation and Growth in Seeded Semibatch Miniemulsion Polymerization of Hybrid CeO2/Acrylic Latexes. Polymer. 2014, 55, 752-761.

(55) Kuchibhatla, S. V. N. T.; Karakoti, A. S.; Baer, D. R.; Samudrala, S.; Engelhard, M. H.; Amonette, J. E.; Thevuthasan, S.; Seal, S. Influence of Aging and Environment on Nanoparticle Chemistry: Implication to Confinement Effects in Nanoceria. J. Phys. Chem. C 2012, 116, 14108-14114.

(56) Lavkova, J.; Khalakhan, I.; Chundak, M.; Vorokhta, M.; Potin, V.; Matolin, V.; Matolinova, I. Growth and Composition of Nanostructured and Nanoporous Cerium Oxide Thin Films on a Graphite Foil. Nanoscale. 2015, 7, 4038-4047.

(57) Routh, A. F.; Russel, W. B. Horizontal Drying Fronts during Solvent Evaporation from Latex Films. AIChE J. 1998, 44, 2088-2098.

(58) Harris, D. J.; Conrad, J. C.; Lewis, J. a. Evaporative Lithographic Patterning of Binary Colloidal Films. Philos. Trans. A. Math. Phys. Eng. Sci. 2009, 367, 5157-5165.

(59) Staehelin, J.; Harris, N. R. P.; Appenzeller, C.; Eberhard, J. Ozone Trends: A Review. Rev. Geophys. 2001, 39, 231-290.

(60) Agarwal, N.; Farris, R. J. Water Absorption by Acrylic-Based Latex Blend Films and Its Effect on Their Properties. J. Appl. Polym. Sci. 1998, 1407-1419.

(61) Butler, L. N.; Fellows, C. M.; Gilbert, R. G. Effect of Surfactant Systems on the Water Sensitivity of Latex Films. J. Appl. Polym. Sci. 2004, 92, 1813-1823.

(62) Van Der Wel, G. K.; Adan, O. C. G. Moisture in Organic Coatings - a Review. Prog. Org. Coatings. 1999, 37, 1-14.

(63) Ping, Z. H.; Nguyen, Q. T.; Chen, S. M.; Zhou, J. Q.; Ding, Y. D. States of Water in Different Hydrophilic Polymers - DSC and FTIR Studies. Polymer. 2001, 42, 8461-8467. 
(64) Lei, Y.; Child, J. R.; Tsavalas, J. G. Design and Analysis of the Homogeneous and Heterogeneous Distribution of Water Confined within Colloidal Polymer Particles. Colloid Polym. Sci. 2012, 291, 143-156.

(65) Jiang, B.; Tsavalas, J.; Sundberg, D. Measuring the Glass Transition of Latex-Based Polymers in the Hydroplasticized State via Differential Scanning Calorimetry. Langmuir. 2010, 26, $9408-9415$.

(66) Tsavalas, J. G.; Sundberg, D. C. Hydroplasticization of Polymers: Model Predictions and Application to Emulsion Polymers. Langmuir. 2010, 26, 6960-6966.

(67) Robert C Weast. CRC Handbook of Chemistry and Physics, 62nd ed.; CRC Press, 1981.

(68) Liu, Y.; Gajewicz, A. M.; Rodin, V.; Soer, W. J.; Scheerder, J.; Satgurunathan, G.; Mcdonald, P. J.; Keddie, J. L. Explanations for Water Whitening in Secondary Dispersion and Emulsion Polymer Films. J. Polym. Sci. Part B Polym. Phys. 2016, 1658-1674.

\section{TABLE OF CONTENTS GRAPHIC}
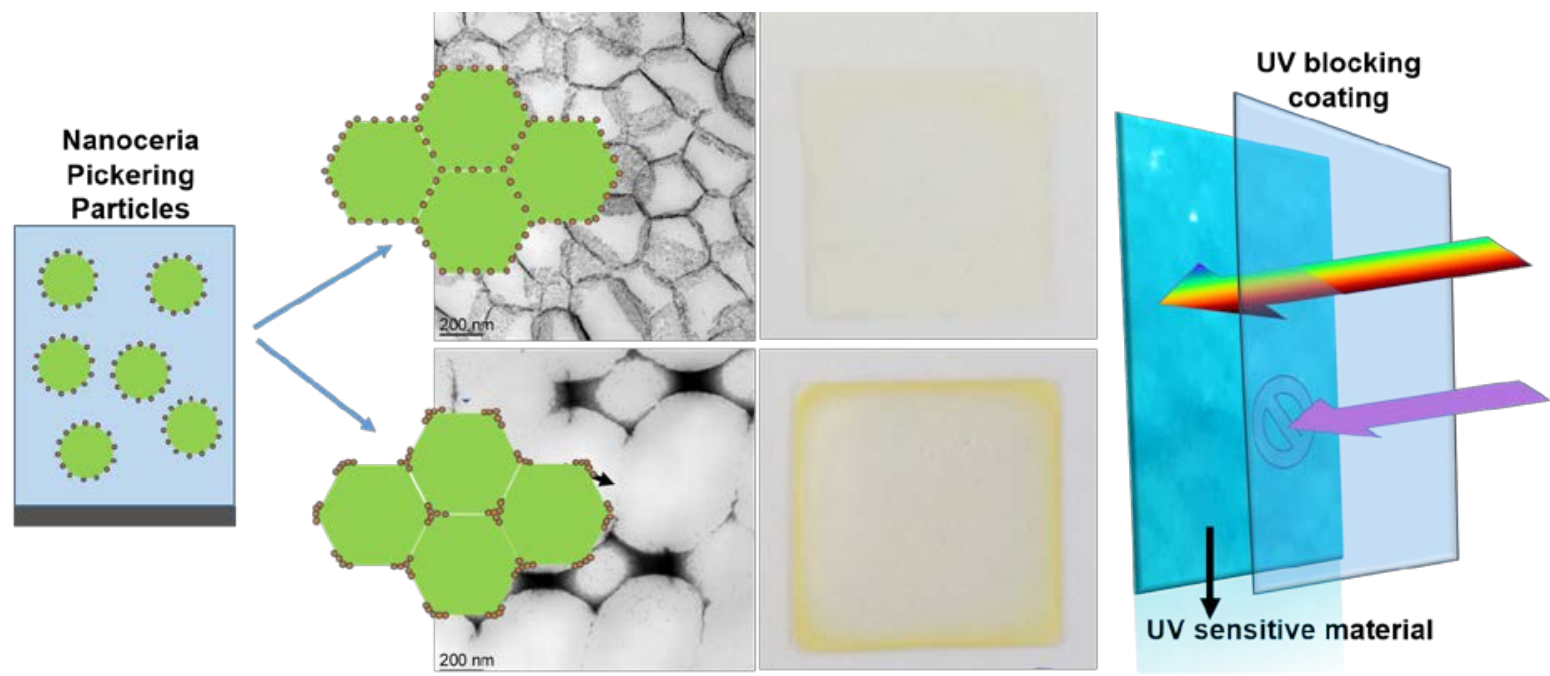